\title{
The C99 domain of the amyloid precursor protein is a disordered membrane phase-preferring protein
}

\author{
Ricardo Capone $^{1,2,3, *}$, Ajit Tiwari ${ }^{3, \#, *}$, Arina Hadziselimovic ${ }^{1}$, Yelena Peskova ${ }^{4}$, James M. \\ Hutchison $^{1}$, Charles R. Sanders ${ }^{1,2,5}$, and Anne K. Kenworthy ${ }^{3,4, \#}$ \\ ${ }^{1}$ Department of Biochemistry, Vanderbilt University, Nashville, TN, 37240 USA \\ ${ }^{2}$ Center for Structural Biology, Vanderbilt University, Nashville, TN, 37240 USA \\ ${ }^{3}$ Department of Molecular Physiology and Biophysics, Vanderbilt University, Nashville, TN, 37232 \\ ${ }^{4}$ Center for Membrane and Cell Physiology, University of Virginia, Charlottesville, VA, 22903 USA \\ ${ }^{e}$ Department of Medicine, Vanderbilt University Medical Center, Nashville, TN, 37232 USA
}

\begin{abstract}
*These authors contributed equally to this study.
\# Current address: Department of Molecular Physiology and Biological Physics and Center for Membrane and Cell Physiology, University of Virginia, Charlottesville, VA, 22903 USA
\end{abstract}

For correspondence: Anne K. Kenworthy, akk7hp@virginia.edu.

Running title: C99 prefers disordered membrane domains

Keywords: Alzheimer's disease, amyloid precursor protein, gamma secretase, lipid raft, membrane bilayer, confocal microscopy 


\begin{abstract}
Processing of the amyloid precursor protein (APP) via the amyloidogenic pathway is associated with the etiology of Alzheimer's disease. The cleavage of APP by $\beta$-secretase to generate the transmembrane 99-residue $\mathrm{C}$ terminal fragment (C99) and subsequent processing of $\mathrm{C} 99$ by $\gamma$-secretase to yield amyloid- $\beta(A \beta)$ peptides are essential steps in this pathway. Biochemical evidence suggests amyloidogenic processing of C99 occurs in cholesterol- and sphingolipid-enriched liquid ordered phase membrane raft domains. However, direct evidence that C99 preferentially associates with rafts has remained elusive. Here, we test this idea by quantifying the affinity of C99-GFP for raft domains in cell-derived giant plasma membrane vesicles. We find that C99 is essentially excluded from ordered domains in HeLa cells, SH-SY5Y cells and neurons, instead exhibiting a strong (roughly 90\%) affinity for disordered domains. The strong association of C99 with disordered domains occurs independently of its cholesterol binding activity, homodimerization, or the familial Alzheimer disease Arctic mutation. Finally, we confirm previous studies suggesting that C99 is processed in the plasma membrane by $\alpha$-secretase, in addition to the well-known $\gamma$-secretase. These findings suggest that C99 itself lacks an intrinsic affinity for raft domains, implying either that amyloidogenic processing of the protein occurs in disordered regions of the membrane, that processing involves a marginal sub-population of C99 found in rafts, or that as-yet-unidentified protein-protein interactions involving C99 in living cells drive it into rafts to promote its cleavage therein.
\end{abstract}

\section{Introduction}

Alzheimer's disease is a progressive neurodegenerative disorder causing dementia that afflicts around 40-50 million persons worldwide (1). The amyloid precursor protein (APP), one of the key transmembrane proteins associated with Alzheimer's disease, undergoes a complex and competing series of proteolytic processing events (2-5). APP is predominantly processed via the non-amyloidogenic pathway, in which APP is first cleaved by $\alpha$-secretase in the middle of the amyloid forming sequence to release an 83 residue $\mathrm{C}$-terminal fragment $(\mathrm{C} 83)$, followed by cleavage of $\mathrm{C} 83$ in its transmembrane domain by $\gamma$-secretase. The amyloidogenic pathway involves sequential cleavage of APP first by $\beta$ secretase, also known as $\beta$-site amyloid precursor protein cleaving enzyme 1 (BACE1). BACE1 cleaves APP to generate a 99 amino acid long transmembrane C-terminal fragment described as APP-CTF $\beta$ or C99. C99 is then processively cleaved by $\gamma$-secretase $(6,7)$, ultimately generating 40-mer $\mathrm{A} \beta 40$ and 42-mer A $\beta 42$ peptides in addition to several less abundant species $(8,9)$. The $A \beta$ peptides aggregate and form oligomers that trigger a series of events resulting in synaptic dysfunction and, ultimately, neuron cell death causing progressive memory loss in Alzheimer's patients. A $\beta$ oligomers go on to aggregate and seed the amyloid plaque deposits that are detected in the brain of Alzheimer's disease patients (10-12).

A variety of evidence suggests that amyloidogenic processing of APP occurs in lipid (membrane) raft domains (13-18). Current models suggest rafts are dynamic cholesterol and sphingolipid-enriched nanoscopic membrane domains that share features of ideal liquid ordered (Lo) membrane domains and function to compartmentalize cellular processes [for recent reviews, see (19-21)]. Early biochemical studies employing detergent-resistant membranes (DRMs) as a measure of raft association suggested that a fraction of APP and its Cterminal fragments, along with $\beta$-secretase and $\gamma$-secretase enzymes, are localized within lipid raft fractions to varying degrees (22-35). Studies using cholesterol depletion to compromise the integrity of lipid rafts have shown that $\beta$-secretase mediated processing of APP is reduced in absence of cholesterol, leading to the suggestion that the amyloidogenic pathway is cholesterol dependent and thus raft dependent as well $(13,36-$ 38). The final proteolytic event of the amyloidogenic pathway, cleavage of C99 by $\gamma$ secretase to release $A \beta$, also has been proposed to be raft dependent $(39,40)$. This model is based in part on observations that the C99 C-terminal fragment of APP is present in detergent insoluble or detergent resistant membranes in some cell 
types, which also led to the suggestion they may contain raft targeting traits $(28,34)$. However, it has long been argued that DRMs cannot be directly equated with lipid rafts $(19,41,42)$. Cholesterol depletion is also an inconclusive test for whether a particular process is raft associated, as the methods use do not necessarily remove only cholesterol from raft domains, and are known to affect a variety of cellular pathways and properties of cell membranes $(43,44)$. Studying rafts in living cells also remains an ongoing challenge (19-21). Thus, complementary approaches are needed to establish the localization of the components of the amyloidogenic pathway within distinct membrane domains and to illuminate possible roles for rafts in Alzheimer's disease.

Biophysical studies from our group have shown cholesterol directly binds to C99 $(18,45)$, raising the intriguing possibility that this could serve as a signal that enables C99 to associate with lipid rafts. To test this idea, in previous work we investigated the preferred localization of C99 in raft versus non-raft phases in synthetic giant unilamellar vesicles (GUVs) generated from a ternary lipid mixture that supports the formation of co-existing liquid-ordered (Lo) and liquid disordered (Ld) domains (46). The results of those studies showed that purified C99 is predominantly localized to non-raft Ld domains in this system. More recently, the phase preference of a $\gamma$-secretase substrate consisting of the C-terminal 76 residues of APP for Lo versus Ld domains was evaluated following its direct insertion into supported lipid bilayers using atomic force microscopy (47). Interestingly, the substrate was found to associate with both ordered and disordered domains, with a preference for ordered domains. However, it is unclear if these studies report on the phase preference of C99 itself since this construct is 23 residues shorter than C99. In addition, both of these studies were carried out in model membrane systems lacking the full complexity of biological membranes. Whether C99 has an intrinsic affinity for associating with ordered domains in cell membranes thus remains an open question.
To further investigate this issue, we here utilize giant plasma membrane vesicles (GPMVs) as a model. Derived from the plasma membrane of live cells, these $\mu \mathrm{m}$-sized vesicles have served as a useful model system to investigate mechanisms that regulate membrane phase behavior and control the localization of lipids and membraneassociated proteins with raft versus non-raft domains (48-54). Similar to biomimetic model membranes such as GUVs, GPMVs can undergo fluid-fluid phase separation into two coexisting domains: a raft-like ordered (Lo-like) phase and non-raft disordered (Ld-like) phase. These domains can sort exogenous as well as native protein and lipids and can be readily visualized and analyzed using conventional fluorescence microscopy techniques (48-51). Typically, such measurements are carried out at room temperature or lower, where the domains are microns in size. Importantly however, even at temperatures above the miscibility transition temperature where GPMVs appear by fluorescence microscopy to consist of a single membrane phase, the presence of nanoscopic domains can be detected $(55,56)$. Furthermore, GPMVs maintain compositional complexity that is similar to native cellular membranes $(48,51,52)$. GPMVs thus better reflect the complex environment of cell membranes and represent a more physiologically relevant model to study the localization or association of proteins with raft-like ordered domains versus disordered domains.

To establish the membrane domain phase preference of C99 in a complex cellular membrane environment, we studied GFP-tagged C99 in GPMVs derived from HeLa cells and the neuroblastoma cell line SH-SY5Y as well as in its differentiated neurons. We show that overexpressed C99-GFP has a strong preference for the disordered phase of GPMVs. Moreover, the high preference of $\mathrm{C} 99$ for the disordered phase is not only independent of cell type but also independent of C99 dimerization, does not require an intact cholesterol binding domain, and is unchanged in a disease-associated mutant form of C99 that contains the Artic E693G mutation. These findings suggest that C99 lacks an intrinsic affinity for raft domains and that localization of C99 to ordered domains may not be required for 
further processing along the amyloidogenic pathway.

\section{Results}

Treatment of cells with $\gamma$-secretase inhibitor enables visualization of C99-GFP in GPMV membranes

To determine whether C99 preferentially resides within raft-like ordered or non-raft disordered domains in GPMVs, we initially utilized HeLa cells, in which APP and C99 have commonly been studied $(57,58)$. In addition, a significant fraction of HeLa cell-derived GPMVs are known to contain micron-scale coexisting ordered (raftlike) and disordered (non-raft) phases at room temperature (59-61), making them an excellent model to quantify the phase preference of specific proteins and lipids. The degree of raft association of a given protein within GPMVs is typically assessed by comparing its localization to that of ordered or disordered phase-specific marker dyes $(48,49,52,62)$.

To visualize C99, we utilized a version of C99 tagged with EGFP on its C-terminus (C99-EGFP) that has been shown to be correctly recognized by $\gamma$-secretase as a substrate (57). When C99-EGFP was overexpressed in HeLa cells, the protein accumulated in the perinuclear region and was mainly excluded from the plasma membrane (Supporting Figure S1A). In contrast, upon treatment of HeLa cells with the $\gamma$-secretase inhibitor DAPT for $24 \mathrm{~h}$, some C99-EGFP accumulated on the plasma membrane (Supporting Figure S1B), in agreement with previous studies $(63,64)$.

Next, we generated GPMVs from HeLa cells transiently overexpressing C99-EGFP. The transfected cells were either treated with vehicle (DMSO) or with $20 \mu \mathrm{M}$ DAPT for $24 \mathrm{~h}$ prior to the preparation of GPMVs, and GPMVs were generated in the continued presence of the inhibitors. The isolated GPMVs were subsequently labeled with $\mathrm{DiD}$, a lipid-based dye and a known disordered phase marker $(53,65)$ and then analyzed using confocal microscopy. Consistent with the absence of C99 in the plasma membrane in intact cells under control conditions, we were unable to detect C99 in the membrane of GPMVs prepared from HeLa cells in the presence of DMSO (Figure 1A, E). Instead, the GFP signal was concentrated in the lumen of the GPMVs (Figure 1A, E). This suggests that C99-EGFP is proteolytically processed to release a soluble cytoplasmic fragment containing GFP prior to and/or during the preparation of the GPMVs. In contrast, in DAPT-treated GPMVs, we also observed membrane-associated fluorescence signal, indicating that at least a fraction of the C99-EGFP cleavage seen in non-treated cells is due to $\gamma$ secretase (Figure 1B).

Analysis of phase-separated GPMVs from DAPT-treated cells that were co-stained with the disordered phase marker DiD revealed that C99EGFP colocalized with $\mathrm{DiD}$, and hence preferentially resided in the disordered phase (Figure 1F). Essentially no GFP signal could be detected in ordered domains, indicating the protein has a very strong preference for disordered domains (Figure 1F). This was verified across several independent experiments in which we quantified the ordered phase preference of C99-EGFP in multiple GPMVs by calculating the ordered domain partitioning fraction $P_{\text {ordered }}$ as described in the Materials and Methods (Supporting Figure S2). In this analysis, a $P_{\text {ordered }}$ between 0 and 0.5 means the protein prefers the non-raft phase, whereas $P_{\text {ordered }}$ between 0.5 and 1.0 is indicative of a raftpreferring protein. $P_{\text {ordered }}$ for C99-EGFP was strongly non-raft preferring, $0.12 \pm 0.05$ (Fig. 1I, $\mathrm{v}=23$ vesicles). In comparison, the non-raft domain marker DiD itself had a $P_{\text {ordered }}$ of $\sim 0.25$ both in vehicle-treated GPMVs and in DAPTtreated GPMVs (Figure 1J).

We noticed that in GPMVs treated with DAPT some GFP fluorescence could still be observed in the lumen, despite using the inhibitor at concentrations above those previously reported to yield maximal protection of EGFP-C99 from cleavage by $\gamma$-secretase (57). The presence of luminal GFP in GPMVs even when the $\gamma$ secretase inhibitor DAPT was present was unexpected since $\gamma$-secretase inhibition should in principle prevent processing of C99 to liberate 
the soluble fragments. We therefore considered the possibility that this may be related to properties of the C99-EGFP construct itself. Inspection of the construct revealed a Kozak sequence upstream of the GFP moiety. To rule out the possibility that free GFP was being expressed without C99 we deleted the Kozak sequence and the first methionine of EGFP. We simultaneously mutated alanine at 206 to lysine (A206K) to generate mEGFP to prevent possible EGFP-induced dimerization (66). We refer to this optimized version as C99-mEGFP in subsequent experiments.

Like C99-EGFP, C99-mEGFP was localized primarily in the perinuclear region in HeLa cells under control conditions and became enriched in the plasma membrane in response to DAPT treatment (Supporting Figure S1). The fluorescence signal for C99-mEGFP was again found exclusively in the lumen of GPMVs derived from cells treated with DMSO (Figure 1C, G), and partially localized to the membrane for GMPVs from cells treated with DAPT where it was strongly excluded from ordered domains, similar to the behavior of C99-EGFP (Figure 1D, $\mathbf{H}, \mathbf{I})$. These findings further support the notion that C99 prefers to localize to disordered domains over ordered domains.

The finding that some luminal GFP signal was still present in GPMVs derived from DAPTtreated cells expressing C99-mEGFP suggests the protein undergoes additional processing by proteases other than $\gamma$-secretase. We next investigated potential sources of this additional proteolytic activity. Since both C99-EGFP and C99-mEGFP yielded essentially the same results, all further experiments were carried out with C99-mEGFP.

\section{C99-mEGFP is processed by $\alpha$-secretase and caspases in addition to $\gamma$-secretase in HeLa cells}

In addition to being a substrate for $\gamma$-secretase, C99 can also be proteolytically cleaved by several other proteases. Both full length APP and C99 are substrates for caspases, and caspase cleavage of their cytosolic domain releases a soluble C31 fragment $(67,68)$ [reviewed in $(69,70)]$. Notably, C99-EGFP has also been reported to undergo caspase cleavage in $\mathrm{HeLa}$ cells (57). C99 is also a substrate for $\alpha$-secretase, leading to its conversion to $\mathrm{C} 83$ under conditions where $\gamma$-secretase is inhibited $(58,71)$. We hypothesized that one or both of these activities may be contributing to the processing of C99mEGFP.

To establish which proteolytic activities are operative on C99-mEGFP, we performed a series of experiments in which C99-mEGFP transfected cells were treated for $24 \mathrm{~h}$ with DAPT in various combinations with the cell permeable pancaspase inhibitor $\mathrm{z}-\mathrm{VAD}$ and the ADAM10 specific inhibitor GI254023X. The cells were then harvested for western blotting and whole cell extracts were probed with antibodies using an Nterminal specific antibody for $A \beta / C 99$, anti-GFP antibodies, and an antibody against the $\mathrm{C}$ terminal portion of C99 (Figure 2 and Supporting Figures S3 and S4).

C99-mEGFP has a predicted molecular weight of $\sim 38 \mathrm{kDa}$. Under most conditions tested, we detected a band at this molecular weight using an N-terminally specific anti-C99 antibody, suggesting that at least a fraction of C99-mEGFP remained unprocessed in cells. In contrast, when probed using an anti-GFP antibody, a variety of cleavage products could also be observed. In the absence of any inhibitors, only a very faint band of intact C99-mEGFP could be seen in cell extracts by western blot (Figure 2, lane 2), possibly corresponding to intracellular membrane-associated C99 that is excluded from the GPMV preparation. In cells treated with DAPT (lane 3) an increase in intensity of the band corresponding to intact C99-mEGFP could be seen when compared to lane 2 (Figure 2, lane 3). However, we also observed bands running at the expected positions of C83-mEGFP and mEGFP, indicating that additional proteolytic processing of the protein was also occurring.

In the presence of a combination of DAPT and the pan-caspase inhibitor z-VAD (lane 4), we observed two main bands, one corresponding to intact C99-mEGFP and a second, stronger band running at the position expected for C83-mEGFP (Figure 2, lane 4). When a combination of the $\gamma$ secretase inhibitor DAPT and the $\alpha$-secretase 
inhibitor GI2540213X was used, a major band corresponding to full length C99-mEGFP, together with weaker bands running at the position of C83-mEGFP and C31-mEGFP were obtained (Figure 2, lane 5). Finally, in the presence of all three inhibitors (hereafter referred to as triple inhibitor cocktail), the intensity of the C99-mEGFP band increased compared to lane 2 (Figure 2, lane 6) and the intensity of the mEGFP band was diminished. Thus, addition of triple inhibitor cocktail strongly increased the amount of C99-mEGFP and decreased the levels of C31and C83-mEGFP-like bands.

Taken together, these results show that in the presence of DAPT, overexpressed C99-mEGFP is mostly processed both by $\alpha$-secretase (to produce the C83-mEGFP protein) and by caspases (Figure 2, lane 3). This implies that in GPMVs derived from DAPT-treated cells (Figure 1), the membrane-associated form of the protein present is predominantly the $\mathrm{C} 83$ form, and the luminal GFP signal likely consists of a mixture of C31-EGFP, AICD-EGFP, and fluorescent EGFP fragments. Because the highest level of intact C99-mEGFP was seen in cells treated with the triple inhibitor cocktail, this cocktail was used in subsequent studies to preserve C99-mEGFP in the membrane so that its phase preference could be more directly investigated.

\section{C99-mEGFP localizes in the disordered phase of HeLa GPMVs derived in the presence of $\gamma$ - secretase, $\alpha$-secretase, and caspase inhibitors}

We carried out studies in which we jointly inhibited $\gamma$-secretase, $\alpha$-secretase and caspases prior to and during GPMV preparation in order to preserve the $\mathrm{C} 99$ form of the protein at the plasma membrane. In HeLa cells incubated with the triple inhibitor cocktail, C99-mEGFP localized as expected to the plasma membrane (Figure S1 E). We observed that GPMVs could be successfully isolated in the presence of the triple inhibitor cocktail, and that a significant fraction were phase-separated at room temperature (Figure 3A). In the presence of the triple inhibitors, C99mEGFP again strongly co-localized with the disordered phase marker DiD and was essentially excluded from ordered domains, with a $P_{\text {ordered }}$ of
$0.13 \pm 0.09$ (Figure 3B, C). This was similar to the value obtained in GPMVs derived from cells treated with DAPT alone (Figure 1). Thus, over $85 \%$ of both C83-mEGFP (Figure 1) and C99mEGFP (Figure 3) localize into the disordered membrane environment.

$\gamma$-secretase activity as well as $\gamma$-secretase inhibitors are known to modulate cholesterol and lipid metabolism as well as membrane phase behavior $(47,72-74)$. We therefore considered the possibility that the inhibitor treatments could themselves be impacting the phase preference of C99 by changing the properties of the membrane itself. To test this possibility, we asked whether other plasma membrane proteins with known phase preferences are correctly localized in ordered and disordered domains of cells where $\gamma$ secretase activity is inhibited or in cells subjected to treatment with the triple inhibitor cocktail. For these experiments, we utilized YFP-GL-GPI, a GPI-anchored protein known to localize to the ordered phase of GPMVs (49) and transferrin receptor-EGFP (TfR-EGFP), a marker of non-raft domains (75). The results of these studies showed neither DAPT nor the triple inhibitors substantially affected the $P_{\text {ordered }}$ of YFP-GL-GPI or TfR-EGFP (Figure 4). Thus, even in the presence of the inhibitors, the preference of proteins and lipids for ordered and disordered domains was preserved, at least for the representative examples studied here. This implies the localization of C99-mEGFP to disordered domains is not induced by the inhibitor treatment, per se, but instead reflects its intrinsic membrane phase preference.

Disruption of the cholesterol binding site, disruption of the dimerization interface of C99, or introduction of familial Alzheimer's disease mutations in no case changes the preference of C99 for disordered domains

We next examined potential mechanisms that regulate the association of $\mathrm{C} 99$ with disordered domains. Both APP and C99 have been reported to form homodimers (76-80). Purified C99 has also been shown to interact with cholesterol (45), and the cholesterol binding site overlaps with a GXXXG motif that has an established role in dimer formation (80). In addition, multiple 
disease-associated mutations of full-length APP have been identified, many of which reside within these regions of the C99 protein (81-85).

To explore whether cholesterol binding or dimer formation are responsible for C99-mEGFP disordered localization in phase-separated GPMVs, we generated mutations in two sites reported to be required for cholesterol binding, I703A and E693A $(45,86)$. APP/C99-G704 has been also been proposed to be essential for dimer formation as well as cholesterol binding $(45,80)$. We thus also generated a G704L mutant which should disrupt both dimer formation and cholesterol binding (80). Both the cholesterol binding and dimerization mutants of C99 maintained the same disordered-phase preference as wild type C99-mEGFP (Figure 5A-D, F).

We also investigated the effects of a familial Alzheimer's disease mutation on the phase preference of C99. The site E693 is subject to multiple familial APP mutations (81-85). We chose to examine the well-studied E693G mutant (also known as Arctic mutation) (81). In GPMVs, C99-E693G-mEGFP also localized strongly to disordered domains (Figure 5E, F). Overall, these data show that the localization of C99-mEGFP to disordered domains occurs independently of cholesterol binding, dimer formation, or the Arctic mutation.

\section{C99-mEGFP localizes to disordered domains in neuronal membranes}

Up to this point, all of our experiments were performed in GPMVs derived from HeLa cells. To test whether C99-mEGFP shows a similar phase preference in a more physiologically relevant cell model and lipid environment, we examined it in SH-SY5Y cells, a human neuroblastoma cell line that can be differentiated to form neurons by addition of $10 \mu \mathrm{M}$ retinoic acid (RA) $(87,88)$. As for the case of HeLa cells, the SH-SY5Y cells were transfected with C99mEGFP, then treated with triple inhibitor cocktail in order to prevent cleavage of C99 by $\gamma$ secretase, $\alpha$-secretase, and caspases prior to and during the formation of GPMVs.

Since to our knowledge there is no prior literature that addresses whether SH-SY5Y cells form
GPMVs, we first confirmed that GPMVs could indeed be generated from both undifferentiated and differentiated SH-SY5Y cells (Figure 6A). At room temperature, the GPMV membranes appeared to populate a uniform single phase, but phase separation was evident upon lowering the temperature into the $2^{\circ}-14^{\circ} \mathrm{C}$ range. As shown in Figure 6B, in GPMVs isolated from RAdifferentiated neurons, C99-mEGFP shows a variable level of EGFP on the membrane as well as luminal GFP, similar to its behavior in HeLa cells (Figure 3). The transfection efficiency for C99-mEGFP in both SH-SY5Y cells and neurons was low. Nonetheless, we could identify enough phase-separated GPMVs to quantify the phase preference of C99-mEGFP (Figure 6B-D). We obtained $P_{\text {ordered }}$ of $0.10 \pm 0.08(\mathrm{v}=27)$ for GPMVs from undifferentiated SH-SY5Y cells and $0.14 \pm 0.09(\mathrm{v}=16)$ from neurons (Figure 6D). These values are similar to those measured in GPMVs from HeLa cells (Figure 3C). Thus, even in SH-SY5Y cells and differentiated neurons, a more physiologically relevant environment for C99, C99-mEGFP predominantly partitions within non-raft regions of the membrane.

\section{Discussion}

The association of APP and its proteolytic fragments with ordered raft domains has been an area of intense research $(13-18,89,90)$. Previous studies relying on biochemical isolation of DRMs or detergent insoluble membranes have detected the association of C-terminal fragments of APP with rafts to varying degrees $(28,33)$. However, these approaches are known to have multiple pitfalls $(19,41,42,91,92)$, resulting in lack of conclusive evidence for the raft association of C99. Because methods are still not available to reliably investigate the association of proteins with rafts in living cells we here visualized and quantified the affinity of $\mathrm{C} 99$ for raft versus nonraft domains in cell-derived GPMVs $(51,52,54,62)$. While GPMVs do not fully recapitulate all of the features of living cell membranes, they have proven to be a valuable tool to investigate mechanisms that control the affinity of proteins for raft versus non-raft domains, and to our knowledge represent the best 
currently available model to address this question $(49,60,61,93-96)$.

The major conclusion of our study is that C99mEGFP is $85-90 \%$ excluded from raft domains in GPMVs derived from HeLa cells, SH-SY5Y cells, and neurons derived from SH-SY5Y cells. Indeed, we had difficulty even detecting the 10$15 \%$ fraction of C99 present in the ordered or raft phase of GPMVs in our studies. Since C83mEGFP appears to be the predominant APPderived species in cells treated with DAPT alone, our results suggest the same is true for C83EGFP. These results are in agreement with our previous observation that $\mathrm{C} 99$ partitions almost exclusively to non-raft Ld domains in a more simplified synthetic lipid GUV model (46). Our results are at variance, however, from a recent report that an engineered $\gamma$-secretase substrate termed SB4 shows some affinity for ordered domains in supported lipid bilayers, as reported by atomic force microscopy (47). SB4 consists of the 76 C-terminal residues of APP and is thus shorter than $\mathrm{C} 99$, and also contains both an Nterminal AviTag and a C-terminal FLAG tag. Why SB4 appears to behave differently than C99 is not yet clear, but could reflect both different experimental conditions (direct insertion into supported model membranes versus biosynthetic incorporation of the protein into biological membranes in the present work) plus the fact that SB4 is essentially a truncated form of C83 and C99. Further investigation will be required to resolve this question.

In recent years, a number of mechanisms have been identified that help regulate the association of proteins with rafts. One of the most widely recognized is palmitoylation, also known as Sacylation $(50,97)$. Several protein components of the amyloidogenic pathway are palmitoylated, including APP itself $(33,34,98)$. Full length mature APP is palmitoylated within its Nterminal ectodomain on Cys186 and Cys187 (99). However, these APP palmitoylation sites are somewhat unusual in that they are localized to the extracellular (luminal) domain, rather than in the cytoplasmic domain of the protein where most palmitoylation sites of transmembrane proteins are found (99). Palmitoylation has been suggested to regulate APP association with
DRMs and processing in rafts, as well as its dimerization $(99,100)$. Importantly however, the C99 domain of APP lacks any cysteines and can therefore cannot undergo palmitoylation, ruling out the possibility that this form of posttranslational modification determines whether C99 itself associates with rafts.

The length and surface area of the transmembrane domain (TMD) of single-pass transmembrane proteins have also been identified as factors that help control their affinity for raft domains (50). In particular, proteins with longer TMD that also have smaller surface areas tend to exhibit higher raft affinities (50). Based simply on the sequence of its TMD, APP and C99 would be predicted to be more likely to partition within disordered regions of the membrane than in ordered raft domains (50). This is in agreement with what we observed in the experiments of this paper as well as in our previous GUV study (46). We note also a previous paper that reported simulations of a TMD-containing C99 fragment in phaseseparated membranes in which the conclusion was made that $C 99$ preferentially partitions at the interface between the Ld and Lo phases, but does not enter the Lo phase (101). This also was not observed in the our present GPMV or previous GUV studies.

Several previous experimental observations may offer clues as to why C99 shows an overwhelming preference for the disordered phase in phase-separated GUVs and cell-derived GPMVs. First, both experimental and computational studies have shown that the TMD of C99 is flexible $(45,102-107)$. At the same time, C99 has been shown to be adaptable to changes in bilayer thickness, wherein the Cterminus of its TMD has a fixed transmembraneend site (defined by three consecutive lysine residues) but the N-terminus of the TMD helix seems to be energetically tolerant of being either membrane-buried (in thicker bilayers) or water exposed (in thinner bilayers) (108). These observations together suggest that the TMD of C99 is both flexible and adaptable, leading it to prefer the disordered phase for entropic reasons. We also recently completed a study of the structure of C99 when it was "forced" into the raft-like environment provided by sphingomyelin 
and cholesterol-rich bicelles (109). In that study, C99 was seen to populate significant populations of monomer, homodimer, and homotrimer, an observation consistent with the notion that C99 is structurally and energetically frustrated in raftlike bicelles resulting a structural heterogeneity (109).

C99 also contains another structural feature that at first glance might be expected to endow the protein with a significant affinity for cholesterolrich raft domains: a cholesterol binding site $(18,45,86,110)$. The functional consequences of cholesterol binding by C99 are incompletely understood, but recent work suggests C99 regulates cholesterol trafficking and cellular lipid metabolism $(74,111,112)$. Key residues in C99 involved in cholesterol binding lie in the $\mathrm{N}$ terminal helix, N-terminal loop, and extracellular end of the TMD (45). While many proteins are now known to bind to cholesterol $(113,114)$, to our knowledge the raft affinity of only a few examples of cholesterol-binding proteins have been systematically investigated. One of the best characterized examples is Perfringolysin $\mathrm{O}$, a cholesterol-dependent cytolysin that exhibits intermediate affinity for rafts in its membrane inserted form (115). The multipass transmembrane protein peripheral myelin protein 22, which also contains putative cholesterol binding sites, shows a strong preference for partitioning in ordered domains in GPMVs (61). Its preference for residing within rafts, however, is retained even when both cholesterol binding sites are mutated (61). In the current study, we found that either in the presence or absence of an intact cholesterol binding site, C99 is primarily excluded from rafts. This in turn suggests binding of cholesterol per se is not sufficient to sorting of transmembrane proteins into ordered domains. We speculate that cholesterol binding could potentially even serve as a mechanism to sort single pass transmembrane proteins into disordered/non-raft domains, if it induces structural conformations that shorten the length or increase the surface area of the transmembrane region. It should also be recognized that the disordered phase domains in ordered/disordered phase-separated vesicles are cholesterol-rich-

\footnotetext{
${ }^{1}$ A. Tiwari and R. Capone, unpublished observations
}

typically with cholesterol concentrations that approach that present in the ordered phase (116), such that membrane proteins with cholesterol binding sites do not need to partition into the ordered phase in order to satisfy their cholesterol binding potential.

C99 is also known to undergo homodimerization $(78,80,102,117-123)$, a process that been reported to regulate the partitioning of some other proteins into or out of rafts (124-126). Homodimerization of C99 has clear biological consequences: for example, it decreases $\gamma$-secretase cleavage (127) and competes with cholesterol binding $(80,101)$. We therefore asked whether the association of C99 with non-raft domains is regulated by homodimerization. We found that disruption of GFP-induced dimerization by introduction of the A206K mutation into EGFP, or mutation of a key dimer-promoting residue G704 in the TMD of C99 had no effect on the phase preference of the protein. We thus conclude that the localization of C99 to non-raft domains occurs independently of its dimerization state. Preliminary evidence also suggests the disordered preference of C99 was preserved when the C-terminal GFP tag was removed and the protein was instead labeled with an HA tag on its N-terminus (data not shown ${ }^{1}$ ), further confirming that the mEGFP moiety did not affect the localization.

Interactions of C99 with other proteins may also be important to enhance its affinity for rafts. For example, the intracellular domain of flotillin-1, itself thought to be a raft-associated protein by virtue of its association with DRMs, is thought to increase the raft association of APP (25). Notably however, flotillin has been observed to favor the disordered phase in GPMVs, a behavior that may reflect the need for cytoskeletal attachment or membrane asymmetry to help maintain its association with ordered domains in GPMVs (49). It is also important to note that, by definition, only the plasma membrane-associated pool of C99-EGFP is incorporated into GPMVs. Thus, we cannot rule out the possibility that, in intracellular membrane compartments such as endosomes or the Golgi complex, whose lipid 
composition differs from that of the plasma membrane, C99 may behave differently.

Finally, although the primary focus of our study was to investigate the affinity of C99-EGFP for ordered domains, we also were able to follow its proteolytic processing by directly visualizing whether GFP fluorescence was present in the lumen of the GPMVs, localized to the GPMV membrane, or both in the presence or absence of inhibitors. Consistent with the idea that C99 has a short half-life and is rapidly turned over (57,128-130), only luminal GFP fluorescence was observed in the absence of any inhibitors in our experiments. In contrast, the addition of the $\gamma$-secretase inhibitor DAPT led to the accumulation of membrane-associated GFP signal in GPMVs. This membrane-associated form of the protein was most likely C83 rather than $\mathrm{C} 99$, as reported by western blotting of whole cell lysates. Moreover, even in the presence of DAPT, some GFP fluorescence could be observed in the lumen of the GPMVs, leading us to probe for additional proteolytic enzymes in cell lysates. The results of these experiments suggest that C99-mEGFP is processed by both $\alpha$ secretase and caspases in the presence of $\gamma$ secretase inhibitors, confirming previous reports $(57,67,68,71,128,131-134)$. The luminal GFP signal we observed in our experiments thus likely corresponds to a mixture of AICD-mEGFP, C31mEGFP, and GFP itself. Some GFP fluorescence could still be observed in the lumen of GPMVs even in the presence of the triple inhibitor cocktail. This indicates that additional proteolytic processing of the protein evidently occurs, although we did not pursue the identity(ies) of the putative additional proteases. In light of recent reports that GPMVs contain pores that are permeable to some hydrophilic solutes (135), further studies will be required to determine whether these soluble cleavage products are quantitatively retained in the GPMV lumen. It is also currently unclear if proteolytic processing of C99-mEGFP only occurs in unperturbed cells or continues as GPMVs are being prepared and imaged. Nevertheless, our current results raise the possibility that GPMVs may be a useful model to study processing of plasma membrane proteins that undergo proteolytic cleavage to liberate soluble cytoplasmic fragments.

In summary, our results suggest a model in which C99 localizes primarily to non-raft domains. This in turn implies either that cleavage of the protein by $\gamma$-secretase occurs predominantly in disordered regions of the membrane, or that only a minority fraction of $\mathrm{C} 99$ is cleaved in raft domains. Our results also cannot rule out that in living cells, C99 is preferentially localized to ordered domains via protein-protein interactions that are not maintained under conditions of GPMV preps. In future studies, it will be critical to determine whether $\gamma$-secretase does indeed associate with ordered raft domains as previously suggested from biochemical studies or instead also is operative in disordered membrane domains. This is especially important given growing evidence that $\gamma$-secretase exists in complexes with other secretases $(64,136,137)$. Answering these questions will provide important steps forward toward fully understanding how specialized membrane nanodomains contribute to the development of Alzheimer's disease.

\section{Experimental Procedures}

\section{Materials}

The $\gamma$-secretase inhibitor DAPT was obtained from Selleckchem (cat\# S2215). The $\alpha$-secretase (ADAM10) specific inhibitor GI254023X was from Aobiou (cat\# AOB3611). The cell permeable pan-caspase inhibitor $z-V A D$ was purchased from UBPBio (cat\# F7110). HEPES (cat\# H3375) and calcium chloride (cat\# C1016) were purchased from Sigma. Sodium chloride (cat\# BP358-212) and paraformaldehyde (Cat\#O4042-500) were procured from Fisher chemicals. EM grade paraformaldehyde solution (Cat\# 15714) was from Electron Microscopy Sciences, PA. Dithiothreitol was obtained from RPI (cat\# 11000-1.0). Mounting media Prolong (R) Gold antifade with DAPI Molecular probes (Cat\# 8961S) was procured from Cell Signaling Technologies. Prolong Gold antifade reagent without DAPI (cat\# P36930) was purchased from Invitrogen. $\mathrm{DiD}$ was purchased from Thermo Fisher Scientific (cat\# D307). 


\section{Plasmids}

An overview of the plasmids used in this study is provided in Table 1. The plasmid pEGFP-N1C99-GFP, referred here as C99-EGFP, was a gift from Dr. Paola Pizzo (57). Plasmid C99-mEGFP was derived from C99-EGFP. It carries the signal peptide of the human APP gene (MLPGLALLLLAAWTARA) followed directly by the $\beta$-secretase cleavage product of the fulllength human amyloid precursor protein (residues 672-770, C99). A single G-codon spacer connects to the $2^{\text {nd }}$ amino acid codon (Val) of EGFP. The $\mathrm{N}$ terminal EGFP initial Met and Kozak sequence were deleted to minimize alternative ribosomal translational initiation $(138,139)$. To eliminate EGFP-directed dimerization, EGFP was made monomeric by substituting GFP A206K $(66,140)$. The plasmid and its protein product are referred to as C99mEGFP. Using C99-mEGFP as a backbone, four mutants were constructed using a Q5 site directed mutagenesis kit (New England Biolabs), corresponding to APP mutations E693A, E693G, I703A and G704L. YFP-GL-GPI was as described previously $(141,142)$. TfR-EGFP was a gift from Dr. Ilya Levental (75).

\section{Cell culture}

All cells were maintained in a tissue culture incubator with humidified air supplemented with $5 \% \mathrm{CO}_{2}$ at $37^{\circ} \mathrm{C}$. HeLa (ATCC cat\# CCL-2) and SHSY5Y (CRL2266 at passage 27) cells were obtained from ATCC. HeLa cells were maintained in DMEM (Gibco cat\# 11885-084) supplemented with $10 \%$ fetal bovine serum (FBS, Gibco 26140-079), 1\% penicillin/streptomycin $(\mathrm{P} / \mathrm{S})$, and $1 \%$ L-glutamine. SH-SY5Y cells were maintained in 1:1 DMEM/F12 with $15 \mathrm{mM}$ HEPES and Glutamine (Corning cat\# 10-092$\mathrm{CV}$ ) supplemented with $10 \% \mathrm{FBS}$ and $1 \% \mathrm{P} / \mathrm{S}$. Before passaging SH-SY5Y cells, the spent media was collected and centrifuged at $150 \mathrm{xg}$ for 5 minutes to collect the floating fraction (87). Passage of SH-SY5Y cells was not allowed to exceed 15 from the original P27 from ATCC.

SH-SY5Y-derived neurons were obtained from cells grown in plates pre-coated with $0.1 \mathrm{mg} / \mathrm{mL}$ Poly-D-Lysine (Gibco A3890401) to which
50,000 cells $/ \mathrm{cm}^{2}$ were seeded and grown for 2 days to $\sim 75-80 \%$ confluency. Differentiation was initiated by exchanging the SH-SY $5 Y$ media with Neuronal differentiation media $(87,88)$. Differentiating /ed cells were only observed prior to changing to fresh media and were protected from light during handling (143). $80 \%$ of the differentiation media was changed every 2 days. The differentiation media consisted of Neurobasal medium with B27 supplement (Gibco cat\# 17504-044) and 1\% Glutamax (Gibco cat\# 35050-061) from which an aliquot is pre-warmed and freshly supplemented each time to a final concentration of $10 \mu \mathrm{M}$ all trans retinoic acid (ATRA) (MilliporeSigma, cat\# PHR1187). ATRA aliquots were previously prepared in DMSO to a concentration of $3 \mathrm{mg} / \mathrm{mL}(10 \mathrm{mM})$ in an anaerobic chamber, aliquoted, protected from light and stored at $-80^{\circ} \mathrm{C}$.

\section{GPMV preparation}

GPMVs were prepared based on an established protocol (52) with the following modifications. Briefly, $\sim 2.5-3 \times 10^{5}$ HeLa cells were seeded in a $100 \mathrm{~mm}$ plate. $15-24 \mathrm{~h}$ later when the cells had reached $\sim 30-35 \%$ confluency they were transfected with $3 \mu \mathrm{g}$ DNA/100 mm plate using a 3:1 ratio Fugene:DNA with C99-mEGFP plasmids in DMEM media without antibiotics or serum (base media). After 4-6 h, fresh complete media was added. $24 \mathrm{~h}$ after transfection, the complete media was exchanged for fresh media supplemented with either $20 \mu \mathrm{M}$ DAPT alone, a combination of $20 \mu \mathrm{M}$ DAPT, $20 \mu \mathrm{M}$ GI254023X and $200 \mu \mathrm{M} z-\mathrm{VAD}$, or other inhibitor combinations as indicated in the text and figure captions.

After an additional $24 \mathrm{~h}$, when the cells had reached $60-70 \%$ confluency, they were rinsed twice with $7 \mathrm{~mL}$ C99-GPMV buffer supplemented with inhibitors $(50 \mathrm{mM}$ HEPES, $150 \mathrm{mM} \mathrm{NaCl}, 2 \mathrm{mM} \mathrm{CaCl}_{2}, \mathrm{pH} 7.4$, with $20 \mu \mathrm{M}$ DAPT, $20 \mu \mathrm{M}$ GI254023X, $100 \mu \mathrm{M}$ zVAD, with $25 \mathrm{mM}$ PFA and $2 \mathrm{mM}$ DTT). Cells were then incubated in $5 \mathrm{~mL}$ of the same buffer at $37^{\circ} \mathrm{C}$ with gentle shaking at $70 \mathrm{rpm}$ for $1.5 \mathrm{~h}$. Parallel to GPMV formation, four glass coverslips were surface treated as follows: first rinsed twice in $100 \%$ ethanol, rinsed 2-3 times in milliQ water 
and then incubated in $0.1 \%$ BSA dissolved in base GPMV buffer and filtered $(0.2 \mu \mathrm{m})$. Just before use the coverslips were rinsed once in milliQ water and left to air dry.

After $1.5 \mathrm{~h}$, the $5 \mathrm{~mL}$ of C99-GPMV containing buffer was collected, transferred to a $15 \mathrm{~mL}$ tube, and supplemented with $20 \mu \mathrm{M}$ DAPT, $20 \mu \mathrm{M}$ GI254023X, and $1.5 \mu \mathrm{g} / \mathrm{mL}$ DID (Ld phase marker $(53,65)$, diluted from a $1 \mathrm{mg} / \mathrm{mL}$ stock in EtOH). The tube was gently mixed by inversion 2-3 times and decanted for $1 \mathrm{~h}$ at RT, after which a $260 \mu \mathrm{L}$ aliquot of GPMVs was collected near the bottom of the tube to avoid cell debris. The aliquot was added to a sandwich made with two coverslips (Marienfeld GmbH $22 \times 22 \mathrm{~mm}, 1.5 \mathrm{H}$, cat\# 107052) pre-coated with $0.1 \%$ BSA and a 1 $\mathrm{mm}$ silicon spacer (EMS, cat\# 70336-10), and allowed to settle for 40-60 min on a cooling stage directly on the microscope prior to imaging. Inhibitors for caspases, $\gamma$ - and $\alpha$-secretase were present during the entire $\sim 36$ hours including acquisition of images. The final DMSO concentration was held below $0.5 \%$.

The same procedure was used for GPMVs generated from SH-SY5Y or neurons, with the following modifications: for SH-SY5Y cells, $4 \times 10^{6}$ cells $/ 100 \mathrm{~mm}$ plate were seeded and transfections were performed using Lipofectamine 3000 using a 3:2 ratio of Lipofectamine 3000:DNA. For neurons, transfection was performed on the $9^{\text {th }}$ day with differentiation media using a 1:2 ratio of DNA:Neuromag reagent (Ozbiosciences, cat\# NM50500). A total of $2 \mu \mathrm{g}$ DNA/ $60 \mathrm{~mm}$ plates was added directly in the differentiation media, and fresh media was exchanged in after $4 \mathrm{~h}$.

For control experiments, HeLa cells were transiently transfected with YFP-GL-GPI or TfRGFP. $24 \mathrm{~h}$ post transfection cells were treated with either DMSO, DAPT $(20 \mu \mathrm{M})$ or cocktail of inhibitors (20 $\mu$ M DAPT, $20 \mu$ M GI254023X and $200 \mu \mathrm{M} \mathrm{z}$-VAD). 24 hours after addition of DMSO or inhibitor(s), GPMVs were generated in PFA-DTT containing GPMV buffer supplemented with DMSO or inhibitor(s) using a protocol similar to that described above for C99EGFP transfected cells. A $275 \mu \mathrm{L}$ aliquot of GPMVs was collected, placed in between 2 coverslips separated by a $1.0 \mathrm{~mm}$ spacer, and imaged at room temperature using an LSM 880 confocal microscope as described below.

\section{GPMV imaging}

GPMVs were imaged either using a Zeiss LSM 510 confocal microscope or a Zeiss LSM 880 confocal microscope. For experiments performed using the LSM 510, a Plan-Neofluar $40 \mathrm{x} / 1.30$ Oil DIC objective was used. The confocal pinholes were set at $150 \mu \mathrm{m}$ aperture for both channels in all experiments. The fluorophores were excited using the $488 \mathrm{~nm}$ line of a $40 \mathrm{~mW}$ Argon laser set at no more than 5$10 \%$ power (reduced at source to $50 \%$, for final $2.5-5 \%$ ) for EGFP signal, and the $633 \mathrm{~nm}$ line of a $\mathrm{HeNe}$ laser set at no more than $2 \%$ power for DiD. Images were collected at $1-2 x$ zoom for sample overview or 10X digital zoom for quantifying phase partition localization. The stage was cooled using a TS-4 MP from Physitemp Instruments (Clifton, NJ, USA) with a custom-fitted adapter for the LSM-510 stage. The cooling stage was aided by connecting the lines to a refrigerated pump (Neslab Instruments Inc. model RTE-111) set at $10^{\circ} \mathrm{C}$. Images were collected over a nominal temperature range of 4$22^{\circ} \mathrm{C}$ for GPMVs from HeLa cells, $1-20^{\circ} \mathrm{C}$ from $\mathrm{SH}-\mathrm{SY} 5 \mathrm{Y}$ cells and $2-14^{\circ} \mathrm{C}$ from neurons derived from SH-SY5Y cells. Because an oil objective in direct contact with the coverslip was used for these experiments, these temperatures are only approximate.

Imaging of GPMVs containing YFP-GL-GPI and TfR-GFP, and data for Figure 1 for C99-EGFP and C99-mEGFP were collected on an LSM 880 confocal microscope using C-Apochromat 40x/1.2 W Korr FCS M27 objective at room temperature. The confocal pinhole was set to 150 $\mu \mathrm{m}$ aperture for all channels. Single $\mathrm{Z}$ plane images of individual GPMVs at 10x optical zoom were acquired using the $488 \mathrm{~nm}$ laser line for GFP or YFP laser lines and $633 \mathrm{~nm}$ line for DiD. For imaging GPMVs containing YFP-GL-GPI, laser output was set to no more than $2.0 \%$. Laser output for GPMVs with TFR-GFP not more than $6.0 \%$ for $488 \mathrm{~nm}$ and for $633 \mathrm{~nm}$ laser output was no more than $2 \%$. For presentation purposes, images were processed using ImageJ software. 


\section{Quantification of raft association}

Quantification of ordered domain partitioning for DiD, YFP-GL-GPI, and TfR-GFP was carried out essentially as described previously $(60,61,94)$. In brief, a line scan was drawn across the GPMV using Image $\mathrm{J}$ to determine the fluorescence intensity in both the ordered and disordered phases. A moving average of 5 pixels was used to smooth the data. The ordered phase partitioning fraction $\mathrm{P}_{\text {ordered }}$ was then calculated using the fluorescence intensity in the ordered phase $\left(\mathrm{I}_{\text {ordered }}\right)$ and fluorescence intensity in the disordered phase $\left(\mathrm{I}_{\text {disordered }}\right)$ as $(52,53)$

$P_{\text {ordered }}=\frac{I_{\text {ordered }}}{I_{\text {ordered }}+I_{\text {disordered }}} \quad$ Equation 1

In GPMVs containing C99-EGFP and C99mEGFP, GFP fluorescence in the ordered phase was typically extremely low, and individual GPMVs contained variable amounts of GFP fluorescence in their lumen. We therefore modified the analysis of partition coefficients as follows (Supporting Figure S2). Using the Plot Profile function of ImageJ, a line was drawn bisecting each GPMV at a position that sampled both the ordered and disordered domains. The line was extended into surrounding background on either side of each GPMV. Using this approach, the position of the peak fluorescence intensity was readily visualized for DiD in both the disordered phase and the ordered phase, as well as for C99-EGFP in the disordered phase. The fluorescence intensity was averaged across the three pixels at the maximum of each peak and recorded. The mean fluorescence intensity of C99-EGFP or C99-mEGFP in the ordered phase was measured at the position of the three pixels corresponding to the peak DiD fluorescence in the ordered phase. Background fluorescence was determined by averaging across $20-25$ pixels at each end of the line for each channel. The ordered phase partitioning fraction coefficient was then calculated using background-subtracted values for $\mathrm{I}_{\text {ordered }}$ and $\mathrm{I}_{\text {disordered }}$ using the equation above. We also confirmed the ordered phase partitioning fraction measurements for a subset of GPMVs containing C99-mEGFP using a second method based on Azimuthal averaging as described in Supporting Figure S5.

\section{Fluorescence microscopy of fixed cells}

HeLa cells grown on glass coverslips were transfected with C99-EGFP or C99-mEGFP as described above. 24 hours post transfection, cells were treated with DMSO, DAPT $(20 \mu \mathrm{M})$, or a triple inhibitor cocktail consisting of $20 \mu \mathrm{M}$ DAPT ( $\gamma$-secretase inhibitor), $20 \mu \mathrm{M}$ GI254023X ( $\alpha$-secretase inhibitor) and $200 \mu \mathrm{M} \mathrm{z-VAD} \mathrm{(pan}$ caspase inhibitor). After incubating the cells an additional $24 \mathrm{~h}$ with indicated inhibitors, the cells were fixed at $37^{\circ} \mathrm{C}$ for $15 \mathrm{~min}$ in $4 \%$ PFA in DPBS. The coverslips were mounted on a glass slide using Prolong Gold antifade reagent containing DAPI for nuclear staining.

Fluorescence imaging of fixed cells was performed using a Zeiss LSM 880 confocal microscope (Carl Zeiss Microscopy, Inc.; Thornwood, NY) using a Plan-Apochromat 63X/1.4 Oil DIC M20 Zeiss oil immersion objective. Fluorescence was excited using a 405 diode and the $448 \mathrm{~nm}$ line of an Argon $/ 230 \mathrm{~mW}$ laser and fluorescence images were collected using filter sets provided by the manufacturer. For presentation purposes, images were processed using ImageJ software.

\section{Western blotting}

HeLa cells were plated, transfected, and treated with inhibitors exactly as described above for GPMV preparation and were $70-80 \%$ confluent on the day of the experiment. They were placed on ice, rinsed once with $5 \mathrm{~mL}$ ice-cold DPBS containing $200 \mu \mathrm{M} z-\mathrm{VAD}, 20 \mu \mathrm{M}$ DAPT, and 20 $\mu \mathrm{M}$ GI254023SX, and then lysed in $300-450 \mu \mathrm{L}$ Lysis buffer (based on DPBS: $136.9 \mathrm{mM} \mathrm{NaCl}$, $2.67 \mathrm{mM} \mathrm{KCl}, 1.47 \mathrm{mM} \mathrm{KH} \mathrm{KO}_{4}, 8.10 \mathrm{mM}$ $\mathrm{Na}_{2} \mathrm{HPO}_{4}$, supplemented with $50 \mathrm{mM}$ Hepes $\mathrm{pH}$ 7.4, 1\% (w/v), Nonidet P-40 (NP-40), 1\% Triton $\mathrm{X}-100,0.5 \%(\mathrm{w} / \mathrm{v})$ SDS, $2 \mathrm{mM}$ EDTA, and protease inhibitors $100 \mu \mathrm{L}$ Sigma-PI8340, 100 $\mu \mathrm{M}$ DAPT, $100 \mu \mathrm{M}$ GI254023X, $300 \mu \mathrm{M} z-$ VAD, $200 \mu \mathrm{M}$ Pepstatin A, and just before use 2 $\mathrm{mM}$ PMSF). Lysis was performed on ice for 5 minutes. Next, extracts were harvested on ice using a cell scraper into $1.5 \mathrm{~mL}$ tubes and kept on ice, further mixed by pipetting and incubated on ice for an additional $30 \mathrm{~min}$. Samples were 
clarified by centrifugation at $20,000 \mathrm{x} \mathrm{g}$ for 30 min at $4^{\circ} \mathrm{C}$. Supernatant and aliquots for protein quantification were collected into fresh tubes kept on ice, flash frozen in liquid $\mathrm{N}_{2}$ and stored in $80^{\circ} \mathrm{C}$. Protein concentration was determined by Bradford assay (Pierce cat\# 1863028) using a linearized Bradford protocol (144). Western blots were performed using $10 \mu \mathrm{g} /$ lane of extracts, and run on $10 \%$ Bis-Tris acrylamide precast gels (NuPAGE cat\# NP0301) with MES as running buffer. For some experiments, MOPS was used as a running buffer instead of MES to increase resolution of bands between $28-38 \mathrm{kDa}$, at the expense of resolving lower molecular weights.

To detect the N-terminus of $\mathrm{C} 99 / \mathrm{A} \beta$, blots were probed with mouse IgG mAb 82E1 (IBL cat\# 10323; lot 1D-421) used at $0.5 \mu \mathrm{g} / \mathrm{mL}$. The Cterminal domain of C99 was detected using a 1:1000 dilution of APP-CT20, a rabbit polyclonal raised against the last 20 amino acids of APP 751770 (Sigma-Aldrich cat\# 17610). GFP was probed using mouse mAb JL-8 (dilution 1:5000; Takara, cat\# 632381) or rabbit mAb GFP (D5.1) XP (dilution 1:1000; Cell Signaling, cat\# 2956).
To detect actin, blots were probed with mouse IgG1 mAb MCA-5J11 against all actin isoforms (1:1000 dilution, Encorbio, cat\# MCA-5J11).

Protein signal was detected using ECL substrate (Pierce \#32209) incubated at room temperature for $5 \mathrm{~min}$ with gentle hand mixing. Images were acquired using the Amersham Imager 600 (GE) set on chemiluminescence, with high dynamic rage and colorimetric marker options selected.

\section{Statistical analysis}

Measurements of the ordered domain partitioning fraction of C99-EGFP and C99-mEGFP were obtained from 2 or more independent experiments and from at least 2 independent experiments for YFP-GL-GPI and TfR-GFP. $\mathrm{P}_{\text {ordered }}$ values were plotted as notched boxes with error bars showing one standard deviation (SD). Each data point represents a measurement from a single GPMV. The actual numerical values are also reported as mean \pm SD across all independent experiments for each protein and treatment. 
Data Availability-All data either are presented in the article, are in the supporting information, or are available from the corresponding author (Anne K. Kenworthy, akk7hp@virginia.edu) upon request.

Acknowledgements-We thank Krishnan Raghunathan and Nico Fricke for assistance at early stages of this study, the Vanderbilt Cell Imaging Shared Resource (CISR) for access to confocal microscopes and Sean Schaffer for assistance optimizing conditions to image GPMV samples.

Author Contributions - AT and RC data curation; RC, AT, YP, and JMH, formal analysis; RC and AT investigation; AT, RC, and AKK writing-original draft; RC, AT, YP, AH, JMH, AKK, and CRS writereview and editing; AT, RC, and JMH, methodology; AKK, AT, RC, and CRS conceptualization; YP and AH resources; AKK and CRS supervision; AKK and CRS project administration.

Funding and Additional Information-The CISR is supported by NIH grants CA68485, DK20593, DK58404, DK59637, and EY08126. This work was supported by NIH 1RF1 AG056147 to AKK and CRS. JMH was supported by NIH T32 CA00958229 and by F31 AG061984. The content is solely the responsibility of the authors and does not necessarily represent the official views of the National Institutes of Health.

Conflict of Interest-The authors declare no conflict of interests or commercial interests.

Abbreviations - A $\beta$, amyloid- $\beta$; APP, amyloid precursor protein; BACE1, $\beta$-site amyloid precursor protein cleaving enzyme 1; DRM, detergent resistant membrane; GPMV, giant plasma membrane vesicle; GUV, giant unilamellar vesicle; Ld, liquid disordered; Lo, liquid ordered; TfR, transferrin receptor; TMD, transmembrane domain; $v$, number of GPMVs measured. 
Table 1. Constructs used in this study

\begin{tabular}{|l|l|l|}
\hline Construct & Identity & Source \\
\hline C99-EGFP & C99 & Gift from Dr. Paola Pizzo (57) \\
\hline C99-mEGFP & $\begin{array}{l}\text { C99, full APP signal sequence } \\
\text { included, Kozak and 1 } \\
\text { Methionine sequence before } \\
\text { GFP deleted, A206K mutation } \\
\text { introduced into EGFP }\end{array}$ & This study \\
\hline C99-E693A & Cholesterol binding mutant & This study \\
\hline C99-I703A & Cholesterol binding mutant & This study \\
\hline C99-G704L & $\begin{array}{l}\text { Cholesterol binding and } \\
\text { dimerization mutant }\end{array}$ & This study \\
\hline C99-E693G & $\begin{array}{l}\text { Familial Alzheimer's disease } \\
\text { mutation (Arctic) }\end{array}$ & This study \\
\hline YFP-GL-GPI & $\begin{array}{l}\text { Model GPI-anchored protein; } \\
\text { raft marker }\end{array}$ & (141,142). \\
\hline TfR-GFP & $\begin{array}{l}\text { Transferrin receptor; non-raft } \\
\text { marker }\end{array}$ & Gift from Dr. Ilya Levental (75). \\
\hline
\end{tabular}



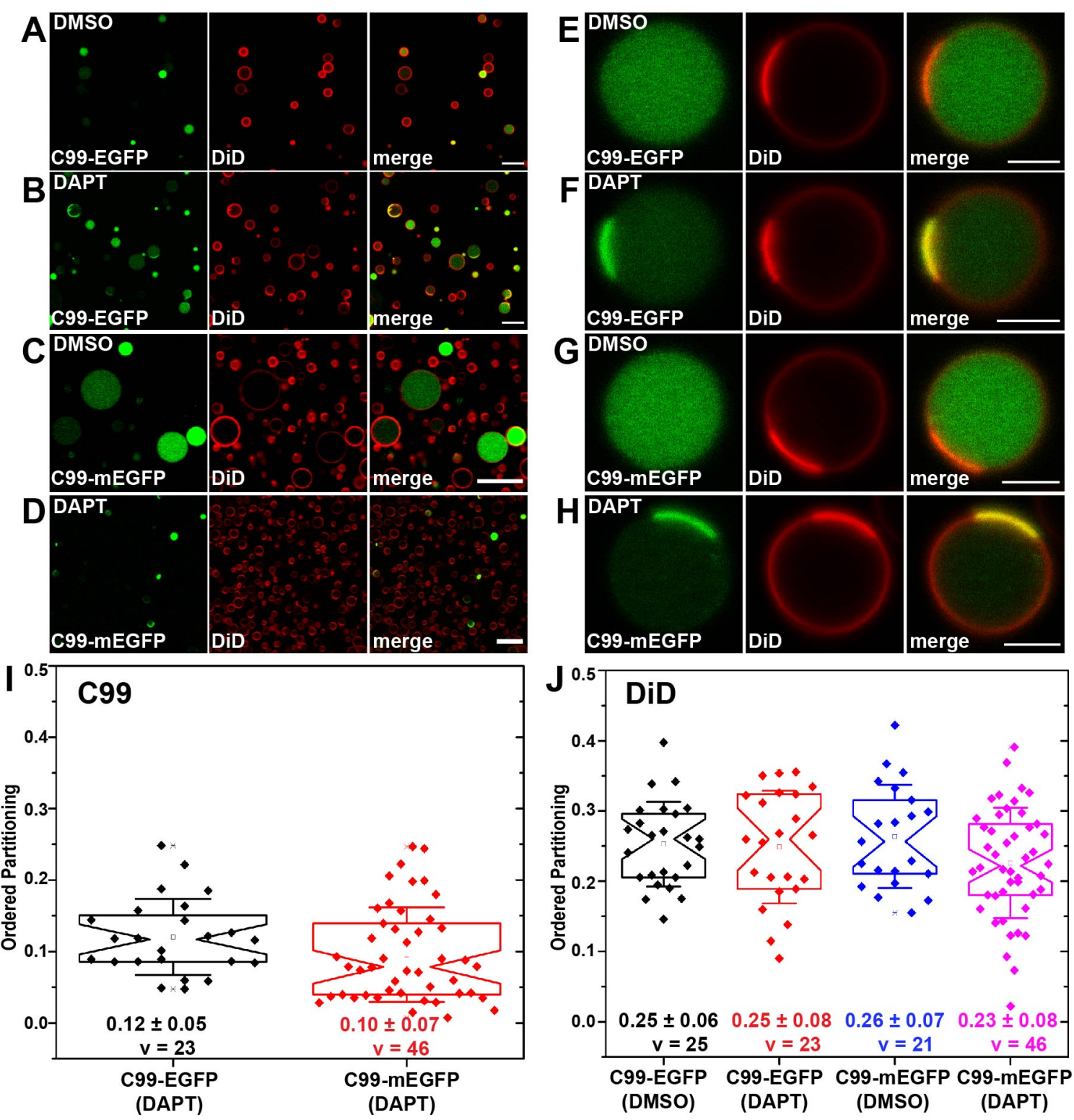

Figure 1. C99-EGFP and C99-mEGFP are excluded from the membrane of GPMVs under control conditions but accumulate in disordered membrane domains in response to $\gamma$-secretase inhibitor (DAPT) treatment. GPMVs were prepared from HeLa cells transfected with C99-EGFP or C99-mEGFP and treated with either DMSO or DAPT for $24 \mathrm{~h}$ prior to and during GPMV preparation. (AD) Representative panorama images of GPMVs containing C99-EGFP (A, B) or C99-mEGFP (C, D) that were treated with either DMSO or DAPT as indicated on the panels. Scale bars, $20 \mu \mathrm{m}$. (EH) Representative images of individual GPMVs treated with either DMSO or DAPT derived from cells expressing C99-EGFP (E, F) or C99-mEGFP (G, H). Scale bars, $5 \mu \mathrm{m}$. In A-H, the disordered phase marker (DiD) is shown in red, and GFP fluorescence is shown in green. (I) Quantification of ordered domain partitioning for C99 in DAPT-treated samples. (J) Quantification of ordered domain partitioning for DiD for samples treated with either DMSO or DAPT, as indicated. $\mathrm{P}_{\text {ordered }}$ values were calculated from 2-3 independent experiments with $>10$ GPMVs analyzed per replicate. Each data point represents a $\mathrm{P}_{\text {ordered }}$ measurement from a single GPMV. The mean $\pm \mathrm{SD}$ is reported on the graph. $\mathrm{v}=$ number of vesicles analyzed. 


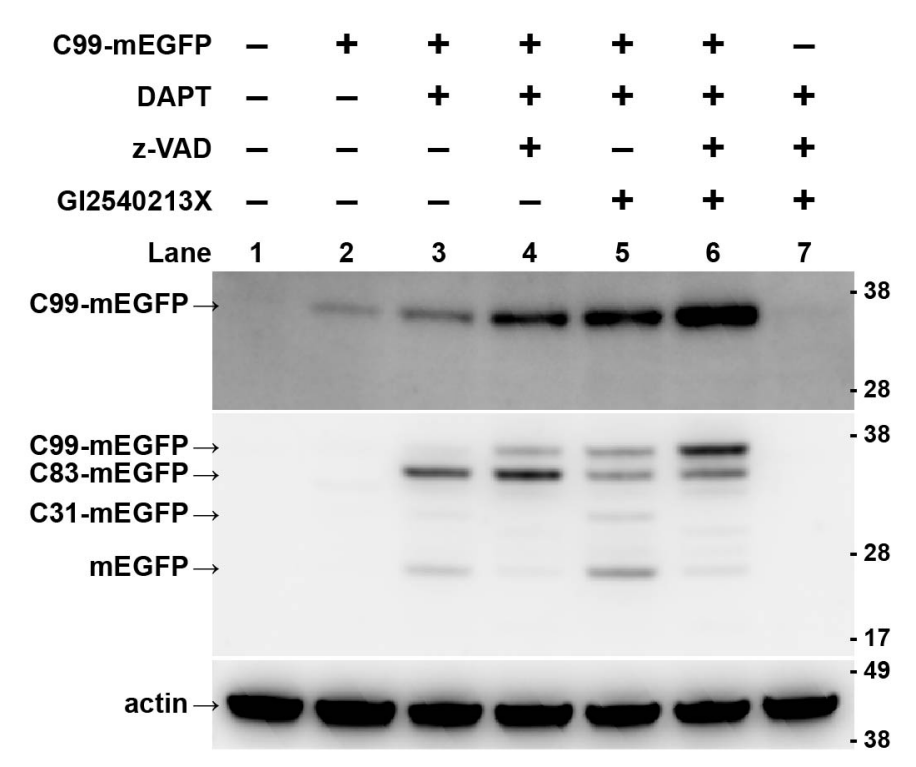

Figure 2. C99-mEGFP is cleaved by $\alpha$-secretase and caspases in addition to $\gamma$-secretase. HeLa cells were either mock transfected or transfected with C99-mEGFP and treated with either DMSO or the indicated inhibitors for $24 \mathrm{~h}$ prior to processing for western blotting. Inhibitors were used at the following concentrations: DAPT $(20 \mu \mathrm{M})$, GI254023X $(20 \mu \mathrm{M})$, and z-VAD $(200 \mu \mathrm{M})$. The final concentration of DMSO in all samples was $0.4 \% .10 \mu \mathrm{g}$ of protein was loaded in each lane. Blots were probed with an Nterminus specific anti-C99 antibody (mAb 82E1; top panel), anti-GFP (mAb JL-8; middle panel), or antiactin (mAb MCA-5J11; bottom panel) as a loading control. Supporting Figure S3 shows the same protein samples probed with anti APP-CT20 and a different anti-GFP antibody. Additionally, images of the complete membranes and total protein staining are available as Supporting Figure S4. 

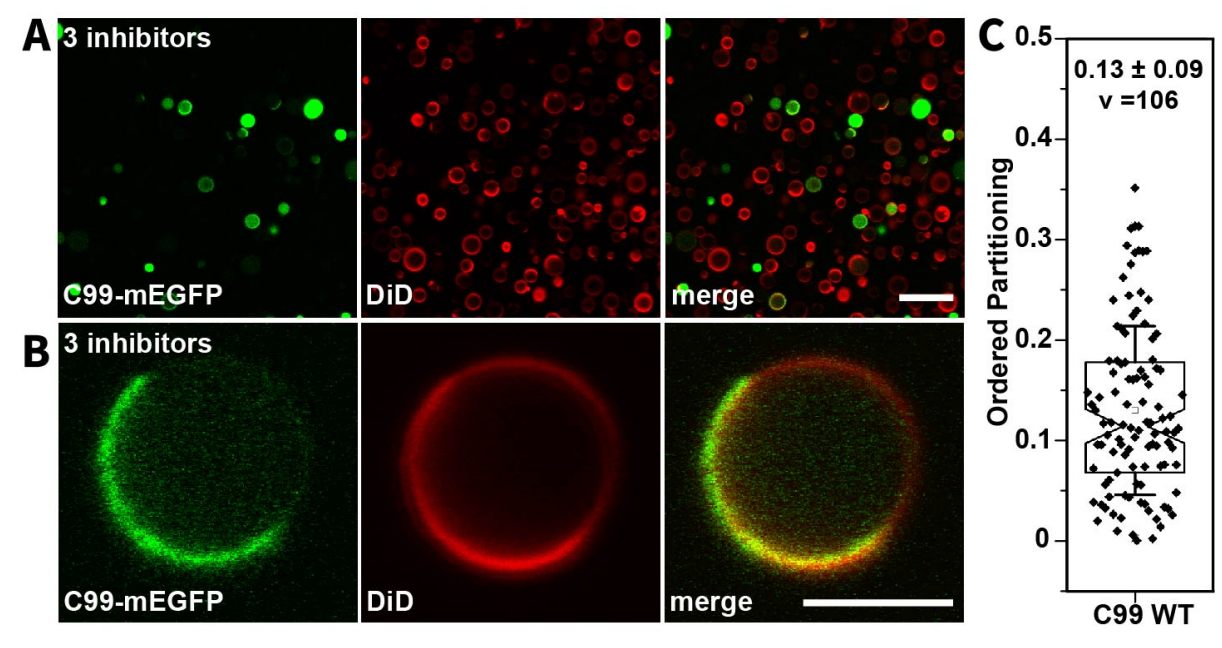

Figure 3. C99-mEGFP shows strong disordered-phase partitioning preference in GPMVs prepared in the presence of a mixture of $\gamma$-secretase, $\alpha$-secretase, and caspase inhibitors. GPMVs were prepared from HeLa cells expressing C99-mEGFP subjected to treatment with a triple inhibitor cocktail as described in the Materials and Methods. (A) Representative image of a field containing multiple GPMVs. Note that some GPMVs exhibit GFP fluorescence primarily in the membrane while in others substantial fluorescence is observed in the GPMV lumen. Scale bar, $20 \mu \mathrm{m}$. (B) Representative image of an individual GPMV demonstrating colocalization of C99-mEGFP (green) with the DiD-positive disordered phase (red). Scale bar, $5 \mu \mathrm{m}$. (C) Quantification of ordered domain partitioning for C99-mEGFP in GPMVs prepared in the continuous presence of the triple inhibitor cocktail. $\mathrm{P}_{\text {ordered }}$ values were calculated from 3 independent experiments. The mean $\pm \mathrm{SD}$ is reported on the graph for $\mathrm{v}$ vesicles. 

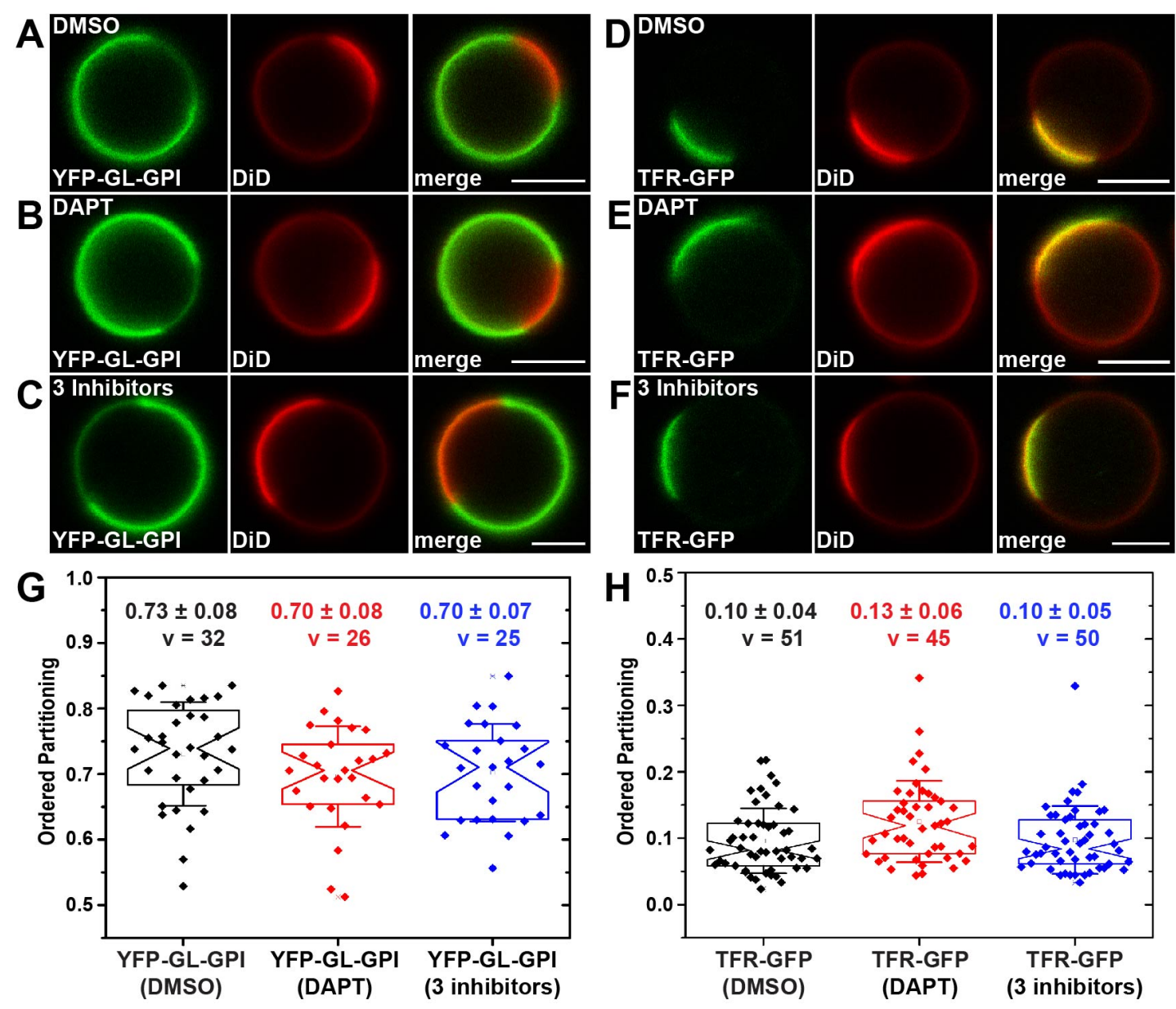

Figure 4. The phase preferences of the raft protein YFP-GL-GPI and non-raft protein TfR-GFP are preserved in the presence of a mixture of $\alpha$-secretase, $\gamma$-secretase, and caspase inhibitors. (A-F) Representative images of individual GPMVs isolated from HeLa cells expressing YFP-GL-GPI (A-C) or TfR-GFP (D-F). GPMVs were prepared in the presence of either DMSO (A, D), DAPT (B, E), or a mixture of $\alpha$-secretase, $\gamma$-secretase and caspase inhibitors $(\mathrm{C}, \mathrm{F})$ as described in the Materials and Methods and imaged at room temperature. Fluorescence of YFP-GL-GPI and TfR-GFP are shown in green and DiD is shown in red. Scale bars, $5 \mu \mathrm{m}$. (G-H) Ordered domain partitioning of YFP-GL-GPI (G) and TfR-GFP obtained in the presence of DMSO, DAPT, or a triple inhibitor cocktail containing $\alpha$-secretase, $\gamma$-secretase, and caspase inhibitors. Ordered domain partitioning was quantified from 2-3 independent experiments with $>10$ GPMVs collected per replicate. Each data point represents a $\mathrm{P}_{\text {ordered }}$ value measured from a single GPMV. The mean \pm SD for $\mathrm{v}$ vesicles is reported on the graph. 


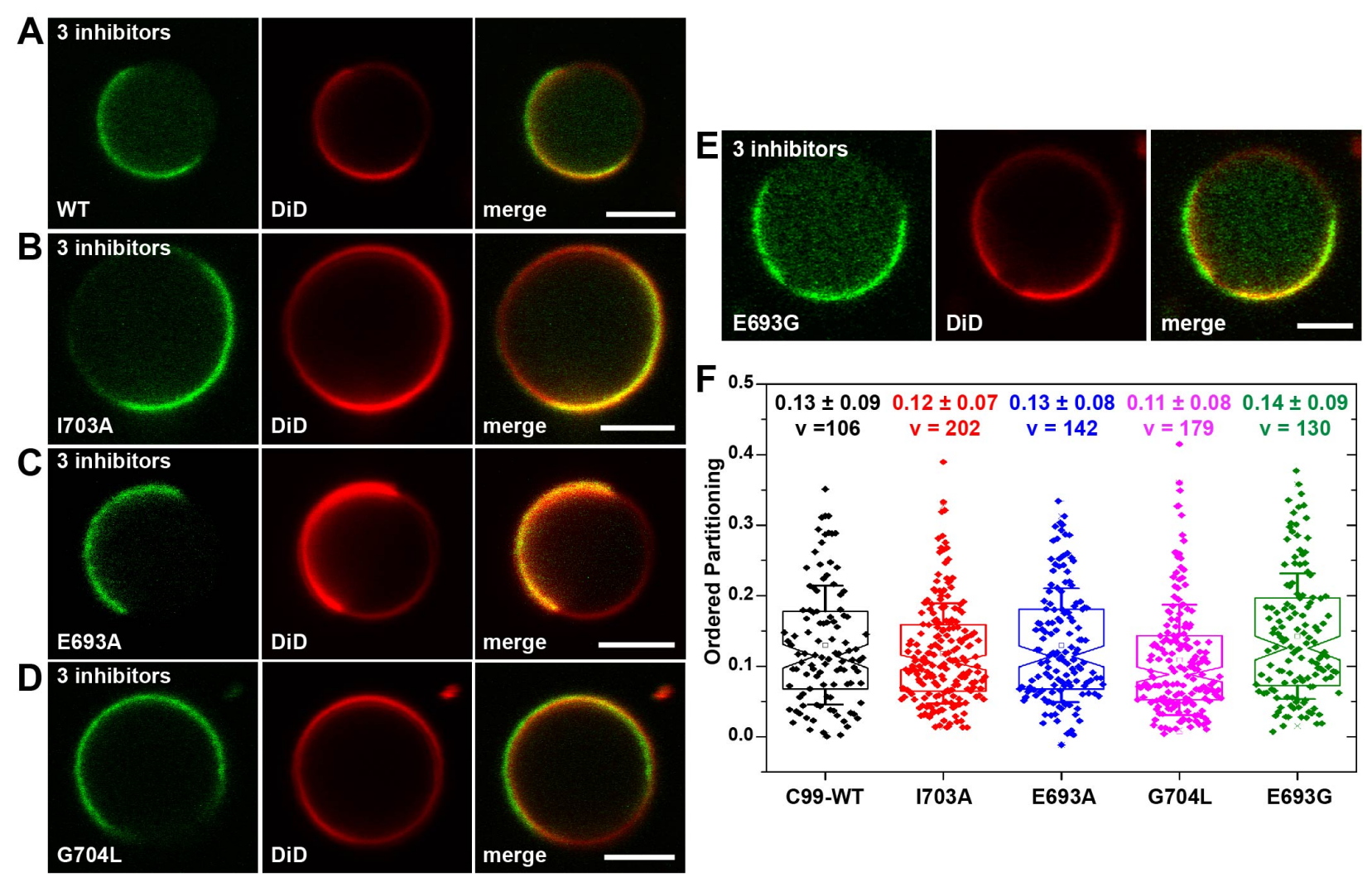

Figure 5. Localization of $\mathrm{C} 99$ in disordered domains occurs independently of its cholesterol binding activity, homodimerization, or the Alzheimer disease-associated Arctic mutation. (A-E) Representative examples of GPMVs derived from HeLa cells expressing either (A) WT C99-mEGFP or the following C99-mEGFP mutants: (B) I703A, a mutation reported to decrease cholesterol binding; (C) E693A, another mutation that disrupts cholesterol binding; (D) G704L, a mutation that disrupts cholesterol binding and the GXXXG dimerization motif; and (E) the familial AD Arctic E693G mutation. In A-E, GFP fluorescence is shown in green and DiD fluorescence is shown in red. Scale bars, $5 \mu \mathrm{m}$. (F) Quantification of ordered domain partitioning for WT C99-mEGFP and its mutants. Pordered values were quantified as described in the Materials and Methods section and in Supporting Figure S1. For each construct, the values given in panel $\mathrm{E}$ represent the mean $\pm \mathrm{SD}$ for v vesicles. The data in the graph for WT C99-mEGFP are reproduced from Figure 3. Each experiment was repeated at least three times. 


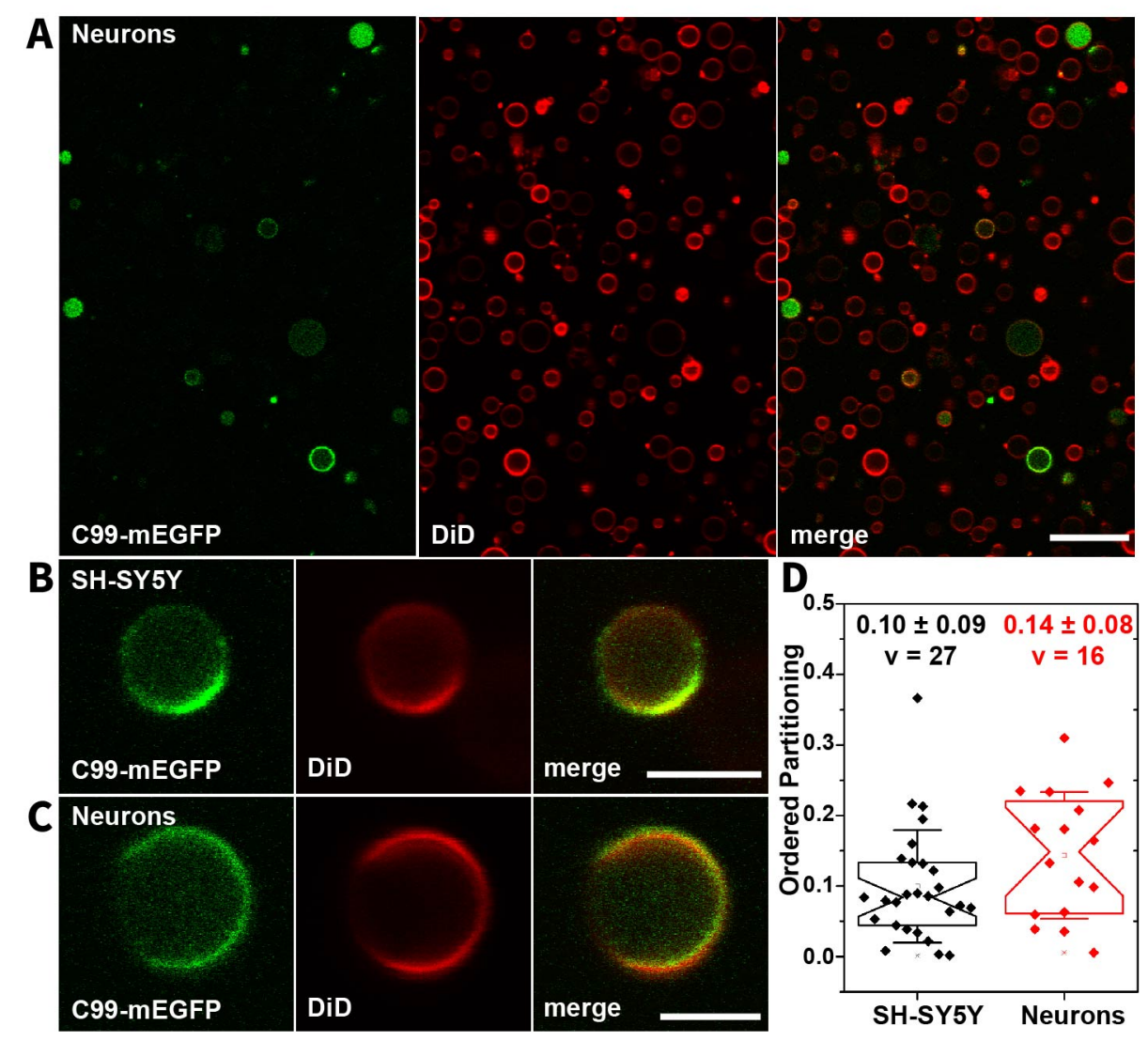

Figure 6. C99-mEGFP localizes in the disordered phase of GPMVs derived from SH-SY5Y cells and SH-SY5Y-derived neurons. (A) Representative panorama image of GPMVs generated from neuronal cells expressing C99-mEGFP. Scale bar, $20 \mu \mathrm{m}$. (B, C) C99-mEGFP shows a strict preference for the disordered phase in GPMVs generated from undifferentiated SH-SY5Y cells (B) or SH-SY5Y-derived neurons generated by retinoic acid differentiation (C) in the continuous presence of a mixture of $\alpha$-secretase, $\gamma$ secretase, and caspase inhibitors. Scale bar, $5 \mu \mathrm{m}$. In A-C, GFP fluorescence is shown in green and DiD fluorescence is red. (D) Ordered domain partitioning of C99-mEGFP in GPMVs derived from undifferentiated SH-SY5Y and SH-SY5Y cells differentiated to form neurons. Images were collected at temperatures between $1-20^{\circ} \mathrm{C}$ for SH-SY5Y cells and $2-14^{\circ} \mathrm{C}$ from neurons derived from $\mathrm{SH}-\mathrm{SY} 5 \mathrm{Y}$ cells to increase the percentage of phase-separated vesicles available for analysis. The numbers given in panel $\mathrm{D}$ represent the mean $\pm \mathrm{SD}$ for $\mathrm{v}$ vesicles. Each experiment was repeated three times. 


\section{Bibliography}

1. Lane, C. A., Hardy, J., and Schott, J. M. (2018) Alzheimer's disease. Eur J Neurol 25, 59-70

2. Castro, M. A., Hadziselimovic, A., and Sanders, C. R. (2019) The vexing complexity of the amyloidogenic pathway. Protein Sci 28, 1177-1193

3. Andrew, R. J., Kellett, K. A., Thinakaran, G., and Hooper, N. M. (2016) A Greek Tragedy: The Growing Complexity of Alzheimer Amyloid Precursor Protein Proteolysis. J Biol Chem 291, 19235-19244

4. Jayne, T., Newman, M., Verdile, G., Sutherland, G., Munch, G., Musgrave, I., Moussavi Nik, S. H., and Lardelli, M. (2016) Evidence For and Against a Pathogenic Role of Reduced gammaSecretase Activity in Familial Alzheimer's Disease. J Alzheimers Dis 52, 781-799

5. Haass, C., Kaether, C., Thinakaran, G., and Sisodia, S. (2012) Trafficking and proteolytic processing of APP. Cold Spring Harb Perspect Med 2, a006270

6. Haass, C., and Selkoe, D. J. (2007) Soluble protein oligomers in neurodegeneration: lessons from the Alzheimer's amyloid beta-peptide. Nat Rev Mol Cell Biol 8, 101-112

7. O'Brien, R. J., and Wong, P. C. (2011) Amyloid precursor protein processing and Alzheimer's disease. Annu Rev Neurosci 34, 185-204

8. Wang, X., Zhou, X., Li, G., Zhang, Y., Wu, Y., and Song, W. (2017) Modifications and Trafficking of APP in the Pathogenesis of Alzheimer's Disease. Front Mol Neurosci 10, 294

9. Wolfe, M. S. (2020) Substrate recognition and processing by gamma-secretase. Biochim Biophys Acta Biomembr 1862, 183016

10. DeTure, M. A., and Dickson, D. W. (2019) The neuropathological diagnosis of Alzheimer's disease. Mol Neurodegener 14, 32

11. Calsolaro, V., and Edison, P. (2016) Neuroinflammation in Alzheimer's disease: Current evidence and future directions. Alzheimers Dement 12, 719-732

12. Selkoe, D. J., and Hardy, J. (2016) The amyloid hypothesis of Alzheimer's disease at 25 years. EMBO Mol Med 8, 595-608

13. Ehehalt, R., Keller, P., Haass, C., Thiele, C., and Simons, K. (2003) Amyloidogenic processing of the Alzheimer beta-amyloid precursor protein depends on lipid rafts. J Cell Biol 160, 113-123

14. Hicks, D. A., Nalivaeva, N. N., and Turner, A. J. (2012) Lipid rafts and Alzheimer's disease: protein-lipid interactions and perturbation of signaling. Front Physiol 3, 189

15. Rushworth, J. V., and Hooper, N. M. (2010) Lipid Rafts: Linking Alzheimer's Amyloid-beta Production, Aggregation, and Toxicity at Neuronal Membranes. Int J Alzheimers Dis 2011, 603052

16. Vetrivel, K. S., and Thinakaran, G. (2010) Membrane rafts in Alzheimer's disease beta-amyloid production. Biochim Biophys Acta 1801, 860-867 
17. Cordy, J. M., Hooper, N. M., and Turner, A. J. (2006) The involvement of lipid rafts in Alzheimer's disease. Mol Membr Biol 23, 111-122

18. Beel, A. J., Sakakura, M., Barrett, P. J., and Sanders, C. R. (2010) Direct binding of cholesterol to the amyloid precursor protein: An important interaction in lipid-Alzheimer's disease relationships? Biochim Biophys Acta 1801, 975-982

19. Sezgin, E., Levental, I., Mayor, S., and Eggeling, C. (2017) The mystery of membrane organization: composition, regulation and roles of lipid rafts. Nat Rev Mol Cell Biol 18, 361-374

20. Levental, I., Levental, K. R., and Heberle, F. A. (2020) Lipid Rafts: Controversies Resolved, Mysteries Remain. Trends Cell Biol 30, 341-353

21. Kusumi, A., Fujiwara, T. K., Tsunoyama, T. A., Kasai, R. S., Liu, A. A., Hirosawa, K. M., Kinoshita, M., Matsumori, N., Komura, N., Ando, H., and Suzuki, K. G. N. (2020) Defining raft domains in the plasma membrane. Traffic 21, 106-137

22. Bouillot, C., Prochiantz, A., Rougon, G., and Allinquant, B. (1996) Axonal Amyloid Precursor Protein Expressed By Neurons In Vitro Is Present In a Membrane Fraction With Caveolae-Like Properties. Journal of Biological Chemistry 271, 7640-7644

23. Parkin, E. T., Hussain, I., Turner, A. J., and Hooper, N. M. (1997) The amyloid precursor protein is not enriched in caveolae-like, detergent-insoluble membrane microdomains. J Neurochem $\mathbf{6 9}$, 2179-2188

24. Lee, S. J., Liyanage, U., Bickel, P. E., Xia, W., Lansbury, P. T., Jr., and Kosik, K. S. (1998) A detergent-insoluble membrane compartment contains A beta in vivo. Nat Med 4, 730-734

25. Chen, T. Y., Liu, P. H., Ruan, C. T., Chiu, L., and Kung, F. L. (2006) The intracellular domain of amyloid precursor protein interacts with flotillin-1, a lipid raft protein. Biochem Biophys Res Commun 342, 266-272

26. Parkin, E. T., Turner, A. J., and Hooper, N. M. (1999) Amyloid precursor protein, although partially detergent-insoluble in mouse cerebral cortex, behaves as an atypical lipid raft protein. Biochem J 344 Pt 1, 23-30

27. Vetrivel, K. S., Cheng, H., Lin, W., Sakurai, T., Li, T., Nukina, N., Wong, P. C., Xu, H., and Thinakaran, G. (2004) Association of gamma-secretase with lipid rafts in post-Golgi and endosome membranes. J Biol Chem 279, 44945-44954

28. Vetrivel, K. S., Cheng, H., Kim, S. H., Chen, Y., Barnes, N. Y., Parent, A. T., Sisodia, S. S., and Thinakaran, G. (2005) Spatial segregation of gamma-secretase and substrates in distinct membrane domains. J Biol Chem 280, 25892-25900

29. Hur, J. Y., Welander, H., Behbahani, H., Aoki, M., Franberg, J., Winblad, B., Frykman, S., and Tjernberg, L. O. (2008) Active gamma-secretase is localized to detergent-resistant membranes in human brain. Febs $J$ 275, 1174-1187

30. Urano, Y., Hayashi, I., Isoo, N., Reid, P. C., Shibasaki, Y., Noguchi, N., Tomita, T., Iwatsubo, T., Hamakubo, T., and Kodama, T. (2005) Association of active gamma-secretase complex with lipid rafts. J Lipid Res 46, 904-912 
31. Riddell, D. R., Christie, G., Hussain, I., and Dingwall, C. (2001) Compartmentalization of betasecretase (Asp2) into low-buoyant density, noncaveolar lipid rafts. Curr Biol 11, 1288-1293

32. Wahrle, S., Das, P., Nyborg, A. C., McLendon, C., Shoji, M., Kawarabayashi, T., Younkin, L. H., Younkin, S. G., and Golde, T. E. (2002) Cholesterol-dependent gamma-secretase activity in buoyant cholesterol-rich membrane microdomains. Neurobiol Dis 9, 11-23

33. Motoki, K., Kume, H., Oda, A., Tamaoka, A., Hosaka, A., Kametani, F., and Araki, W. (2012) Neuronal beta-amyloid generation is independent of lipid raft association of beta-secretase BACE1: analysis with a palmitoylation-deficient mutant. Brain Behav 2, 270-282

34. Vetrivel, K. S., Meckler, X., Chen, Y., Nguyen, P. D., Seidah, N. G., Vassar, R., Wong, P. C., Fukata, M., Kounnas, M. Z., and Thinakaran, G. (2009) Alzheimer disease Abeta production in the absence of S-palmitoylation-dependent targeting of BACE1 to lipid rafts. J Biol Chem 284, 3793-3803

35. Sakurai, T., Kaneko, K., Okuno, M., Wada, K., Kashiyama, T., Shimizu, H., Akagi, T., Hashikawa, T., and Nukina, N. (2008) Membrane microdomain switching: a regulatory mechanism of amyloid precursor protein processing. J Cell Biol 183, 339-352

36. Guardia-Laguarta, C., Coma, M., Pera, M., Clarimon, J., Sereno, L., Agullo, J. M., MolinaPorcel, L., Gallardo, E., Deng, A., Berezovska, O., Hyman, B. T., Blesa, R., Gomez-Isla, T., and Lleo, A. (2009) Mild cholesterol depletion reduces amyloid-beta production by impairing APP trafficking to the cell surface. $J$ Neurochem 110, 220-230

37. Grimm, M. O., Grimm, H. S., Tomic, I., Beyreuther, K., Hartmann, T., and Bergmann, C. (2008) Independent inhibition of Alzheimer disease beta- and gamma-secretase cleavage by lowered cholesterol levels. J Biol Chem 283, 11302-11311

38. Simons, M., Keller, P., De Strooper, B., Beyreuther, K., Dotti, C. G., and Simons, K. (1998) Cholesterol depletion inhibits the generation of beta-amyloid in hippocampal neurons. Proc Natl Acad Sci U S A 95, 6460-6464

39. Matsumura, N., Takami, M., Okochi, M., Wada-Kakuda, S., Fujiwara, H., Tagami, S., Funamoto, S., Ihara, Y., and Morishima-Kawashima, M. (2014) gamma-Secretase associated with lipid rafts: multiple interactive pathways in the stepwise processing of beta-carboxyl-terminal fragment. $J$ Biol Chem 289, 5109-5121

40. Araki, W., and Tamaoka, A. (2015) Amyloid beta-protein and lipid rafts: focused on biogenesis and catabolism. Front Biosci (Landmark Ed) 20, 314-324

41. Lichtenberg, D., Goni, F. M., and Heerklotz, H. (2005) Detergent-resistant membranes should not be identified with membrane rafts. Trends Biochem Sci 30, 430-436

42. Lingwood, D., and Simons, K. (2007) Detergent resistance as a tool in membrane research. Nat Protoc 2, 2159-2165

43. Mahammad, S., and Parmryd, I. (2008) Cholesterol homeostasis in T cells. Methyl-betacyclodextrin treatment results in equal loss of cholesterol from Triton X-100 soluble and insoluble fractions. Biochim Biophys Acta 1778, 1251-1258 
44. Zidovetzki, R., and Levitan, I. (2007) Use of cyclodextrins to manipulate plasma membrane cholesterol content: Evidence, misconceptions and control strategies. Biochim Biophys Acta 1768, $1311-1324$

45. Barrett, P. J., Song, Y., Van Horn, W. D., Hustedt, E. J., Schafer, J. M., Hadziselimovic, A., Beel, A. J., and Sanders, C. R. (2012) The amyloid precursor protein has a flexible transmembrane domain and binds cholesterol. Science 336, 1168-1171

46. Schlebach, J. P., Barrett, P. J., Day, C. A., Kim, J. H., Kenworthy, A. K., and Sanders, C. R. (2016) Topologically diverse human membrane proteins partition to liquid-disordered domains in phase-separated lipid vesicles. Biochemistry 55, 985-988

47. Barros, M., Houlihan, W. J., Paresi, C. J., Brendel, M., Rynearson, K. D., Lee, C. W., Prikhodko, O., Cregger, C., Chang, G., Wagner, S. L., Gilchrist, M. L., and Li, Y. M. (2020) gammaSecretase partitioning into lipid bilayers remodels membrane microdomains after direct insertion. Langmuir 36, 6569-6579

48. Baumgart, T., Hammond, A. T., Sengupta, P., Hess, S. T., Holowka, D. A., Baird, B. A., and Webb, W. W. (2007) Large-scale fluid/fluid phase separation of proteins and lipids in giant plasma membrane vesicles. Proc Natl Acad Sci U S A 104, 3165-3170

49. Sengupta, P., Hammond, A., Holowka, D., and Baird, B. (2008) Structural determinants for partitioning of lipids and proteins between coexisting fluid phases in giant plasma membrane vesicles. Biochim Biophys Acta 1778, 20-32

50. Lorent, J. H., Diaz-Rohrer, B., Lin, X., Spring, K., Gorfe, A. A., Levental, K. R., and Levental, I. (2017) Structural determinants and functional consequences of protein affinity for membrane rafts. Nat Commun 8, 1219

51. Levental, K. R., and Levental, I. (2015) Giant plasma membrane vesicles: models for understanding membrane organization. Curr Top Membr 75, 25-57

52. Sezgin, E., Kaiser, H. J., Baumgart, T., Schwille, P., Simons, K., and Levental, I. (2012)

Elucidating membrane structure and protein behavior using giant plasma membrane vesicles. Nat Protoc 7, 1042-1051

53. Sezgin, E., Levental, I., Grzybek, M., Schwarzmann, G., Mueller, V., Honigmann, A., Belov, V. N., Eggeling, C., Coskun, U., Simons, K., and Schwille, P. (2012) Partitioning, diffusion, and ligand binding of raft lipid analogs in model and cellular plasma membranes. Biochim Biophys Acta 1818, 1777-1784

54. Gerstle, Z., Desai, R., and Veatch, S. L. (2018) Giant Plasma Membrane Vesicles: An Experimental Tool for Probing the Effects of Drugs and Other Conditions on Membrane Domain Stability. Methods Enzymol 603, 129-150

55. Li, G., Wang, Q., Kakuda, S., and London, E. (2020) Nanodomains can persist at physiologic temperature in plasma membrane vesicles and be modulated by altering cell lipids. J Lipid Res 61, 758-766 
56. Heberle, F. A., Doktorova, M., Scott, H. L., Skinkle, A. D., Waxham, M. N., and Levental, I. (2020) Direct label-free imaging of nanodomains in biomimetic and biological membranes by cryogenic electron microscopy. Proc Natl Acad Sci U S A 117, 19943-19952

57. Florean, C., Zampese, E., Zanese, M., Brunello, L., Ichas, F., De Giorgi, F., and Pizzo, P. (2008) High content analysis of gamma-secretase activity reveals variable dominance of presenilin mutations linked to familial Alzheimer's disease. Biochim Biophys Acta 1783, 1551-1560

58. Tan, J. Z. A., and Gleeson, P. A. (2019) The trans-Golgi network is a major site for alphasecretase processing of amyloid precursor protein in primary neurons. J Biol Chem 294, 16181631

59. Johnson, S. A., Stinson, B. M., Go, M. S., Carmona, L. M., Reminick, J. I., Fang, X., and Baumgart, T. (2010) Temperature-dependent phase behavior and protein partitioning in giant plasma membrane vesicles. Biochim Biophys Acta 1798, 1427-1435

60. Raghunathan, K., Foegeding, N. J., Campbell, A. M., Cover, T. L., Ohi, M. D., and Kenworthy, A. K. (2018) Determinants of Raft Partitioning of the Helicobacter pylori Pore-Forming Toxin VacA. Infect Immun 86, e00872-00817

61. Marinko, J. T., Kenworthy, A. K., and Sanders, C. R. (2020) Peripheral myelin protein 22 preferentially partitions into ordered phase membrane domains. Proc Natl Acad Sci US A 117, 14168-14177

62. Levental, K. R., and Levental, I. (2015) Isolation of giant plasma membrane vesicles for evaluation of plasma membrane structure and protein partitioning. Methods Mol Biol 1232, 65-77

63. Zhang, M., Haapasalo, A., Kim, D. Y., Ingano, L. A., Pettingell, W. H., and Kovacs, D. M. (2006) Presenilin/gamma-secretase activity regulates protein clearance from the endocytic recycling compartment. FASEB J 20, 1176-1178

64. Chen, A. C., Kim, S., Shepardson, N., Patel, S., Hong, S., and Selkoe, D. J. (2015) Physical and functional interaction between the alpha- and gamma-secretases: A new model of regulated intramembrane proteolysis. J Cell Biol 211, 1157-1176

65. Klymchenko, A. S., and Kreder, R. (2014) Fluorescent probes for lipid rafts: from model membranes to living cells. Chem Biol 21, 97-113

66. Zacharias, D. A., Violin, J. D., Newton, A. C., and Tsien, R. Y. (2002) Partitioning of lipidmodified monomeric GFPs into membrane microdomains of live cells. Science 296, 913-916

67. Lu, D. C., Rabizadeh, S., Chandra, S., Shayya, R. F., Ellerby, L. M., Ye, X., Salvesen, G. S., Koo, E. H., and Bredesen, D. E. (2000) A second cytotoxic proteolytic peptide derived from amyloid beta-protein precursor. Nat Med 6, 397-404

68. Gervais, F. G., Xu, D., Robertson, G. S., Vaillancourt, J. P., Zhu, Y., Huang, J., LeBlanc, A., Smith, D., Rigby, M., Shearman, M. S., Clarke, E. E., Zheng, H., Van Der Ploeg, L. H., Ruffolo, S. C., Thornberry, N. A., Xanthoudakis, S., Zamboni, R. J., Roy, S., and Nicholson, D. W. (1999) Involvement of caspases in proteolytic cleavage of Alzheimer's amyloid-beta precursor protein and amyloidogenic A beta peptide formation. Cell 97, 395-406 
69. Zhang, Y. W., Thompson, R., Zhang, H., and Xu, H. (2011) APP processing in Alzheimer's disease. Mol Brain 4, 3

70. Bredesen, D. E., John, V., and Galvan, V. (2010) Importance of the caspase cleavage site in amyloid-beta protein precursor. J Alzheimers Dis 22, 57-63

71. Jager, S., Leuchtenberger, S., Martin, A., Czirr, E., Wesselowski, J., Dieckmann, M., Waldron, E., Korth, C., Koo, E. H., Heneka, M., Weggen, S., and Pietrzik, C. U. (2009) alpha-secretase mediated conversion of the amyloid precursor protein derived membrane stub C99 to C83 limits Abeta generation. $J$ Neurochem 111, 1369-1382

72. Grimm, M. O., Tschape, J. A., Grimm, H. S., Zinser, E. G., and Hartmann, T. (2006) Altered membrane fluidity and lipid raft composition in presenilin-deficient cells. Acta Neurol Scand Suppl 185, 27-32

73. Eckert, G. P., and Muller, W. E. (2009) Presenilin 1 modifies lipid raft composition of neuronal membranes. Biochem Biophys Res Commun 382, 673-677

74. Gutierrez, E., Lutjohann, D., Kerksiek, A., Fabiano, M., Oikawa, N., Kuerschner, L., Thiele, C., and Walter, J. (2020) Importance of gamma-secretase in the regulation of liver X receptor and cellular lipid metabolism. Life Sci Alliance $\mathbf{3}$

75. Zhou, Y., Maxwell, K. N., Sezgin, E., Lu, M., Liang, H., Hancock, J. F., Dial, E. J., Lichtenberger, L. M., and Levental, I. (2013) Bile acids modulate signaling by functional perturbation of plasma membrane domains. J Biol Chem 288, 35660-35670

76. Scheuermann, S., Hambsch, B., Hesse, L., Stumm, J., Schmidt, C., Beher, D., Bayer, T. A., Beyreuther, K., and Multhaup, G. (2001) Homodimerization of amyloid precursor protein and its implication in the amyloidogenic pathway of Alzheimer's disease. J Biol Chem 276, 33923-33929

77. Yan, Y., Xu, T. H., Harikumar, K. G., Miller, L. J., Melcher, K., and Xu, H. E. (2017) Dimerization of the transmembrane domain of amyloid precursor protein is determined by residues around the gamma-secretase cleavage sites. J Biol Chem 292, 15826-15837

78. Miyashita, N., Straub, J. E., Thirumalai, D., and Sugita, Y. (2009) Transmembrane structures of amyloid precursor protein dimer predicted by replica-exchange molecular dynamics simulations. $J$ Am Chem Soc 131, 3438-3439

79. Audagnotto, M., Lemmin, T., Barducci, A., and Dal Peraro, M. (2016) Effect of the Synaptic Plasma Membrane on the Stability of the Amyloid Precursor Protein Homodimer. J Phys Chem Lett 7, 3572-3578

80. Song, Y., Hustedt, E. J., Brandon, S., and Sanders, C. R. (2013) Competition between homodimerization and cholesterol binding to the C99 domain of the amyloid precursor protein. Biochemistry 52, 5051-5064

81. Nilsberth, C., Westlind-Danielsson, A., Eckman, C. B., Condron, M. M., Axelman, K., Forsell, C., Stenh, C., Luthman, J., Teplow, D. B., Younkin, S. G., Naslund, J., and Lannfelt, L. (2001) The 'Arctic' APP mutation (E693G) causes Alzheimer's disease by enhanced Abeta protofibril formation. Nat Neurosci 4, 887-893 
82. Kamino, K., Orr, H. T., Payami, H., Wijsman, E. M., Alonso, M. E., Pulst, S. M., Anderson, L., O'Dahl, S., Nemens, E., White, J. A., and et al. (1992) Linkage and mutational analysis of familial Alzheimer disease kindreds for the APP gene region. Am J Hum Genet 51, 998-1014

83. Levy, E., Carman, M. D., Fernandez-Madrid, I. J., Power, M. D., Lieberburg, I., van Duinen, S. G., Bots, G. T., Luyendijk, W., and Frangione, B. (1990) Mutation of the Alzheimer's disease amyloid gene in hereditary cerebral hemorrhage, Dutch type. Science 248, 1124-1126

84. Miravalle, L., Tokuda, T., Chiarle, R., Giaccone, G., Bugiani, O., Tagliavini, F., Frangione, B., and Ghiso, J. (2000) Substitutions at codon 22 of Alzheimer's abeta peptide induce diverse conformational changes and apoptotic effects in human cerebral endothelial cells. J Biol Chem 275, 27110-27116

85. Grabowski, T. J., Cho, H. S., Vonsattel, J. P., Rebeck, G. W., and Greenberg, S. M. (2001) Novel amyloid precursor protein mutation in an Iowa family with dementia and severe cerebral amyloid angiopathy. Ann Neurol 49, 697-705

86. Nierzwicki, L., and Czub, J. (2015) Specific Binding of Cholesterol to the Amyloid Precursor Protein: Structure of the Complex and Driving Forces Characterized in Molecular Detail. J Phys Chem Lett 6, 784-790

87. Bell, N., Hann, V., Redfern, C. P., and Cheek, T. R. (2013) Store-operated Ca(2+) entry in proliferating and retinoic acid-differentiated N- and S-type neuroblastoma cells. Biochim Biophys Acta 1833, 643-651

88. Amini, S., and White, M. K. (eds). (2013) Neuronal Cell Culture: Methods and Protocols, Vol. 1078, Springer Science+Business Media New York

89. Grimm, M. O., Mett, J., Grimm, H. S., and Hartmann, T. (2017) APP function and lipids: a bidirectional link. Front Mol Neurosci 10, 63

90. Fabiani, C., and Antollini, S. S. (2019) Alzheimer's disease as a membrane disorder: spatial crosstalk among beta-amyloid peptides, nicotinic acetylcholine receptors and lipid rafts. Front Cell Neurosci 13, 309

91. Kraft, M. L. (2013) Plasma membrane organization and function: moving past lipid rafts. Mol Biol Cell 24, 2765-2768

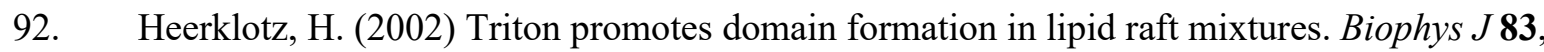
2693-2701

93. Lorent, J. H., and Levental, I. (2015) Structural determinants of protein partitioning into ordered membrane domains and lipid rafts. Chem Phys Lipids 192, 23-32

94. Raghunathan, K., Wong, T. H., Chinnapen, D. J., Lencer, W. I., Jobling, M. G., and Kenworthy, A. K. (2016) Glycolipid crosslinking is required for cholera toxin to partition into and stabilize ordered domains. Biophys $J$ 111, 2547-2550

95. Stone, M. B., Shelby, S. A., Nunez, M. F., Wisser, K., and Veatch, S. L. (2017) Protein sorting by lipid phase-like domains supports emergent signaling function in B lymphocyte plasma membranes. Elife 6 
96. Sengupta, P., Seo, A. Y., Pasolli, H. A., Song, Y. E., Johnson, M. C., and Lippincott-Schwartz, J. (2019) A lipid-based partitioning mechanism for selective incorporation of proteins into membranes of HIV particles. Nat Cell Biol 21, 452-461

97. Levental, I., Lingwood, D., Grzybek, M., Coskun, U., and Simons, K. (2010) Palmitoylation regulates raft affinity for the majority of integral raft proteins. Proc Natl Acad Sci U S A 107, 22050-22054

98. Cheng, H., Vetrivel, K. S., Drisdel, R. C., Meckler, X., Gong, P., Leem, J. Y., Li, T., Carter, M., Chen, Y., Nguyen, P., Iwatsubo, T., Tomita, T., Wong, P. C., Green, W. N., Kounnas, M. Z., and Thinakaran, G. (2009) S-palmitoylation of gamma-secretase subunits nicastrin and APH-1. J Biol Chem 284, 1373-1384

99. Bhattacharyya, R., Barren, C., and Kovacs, D. M. (2013) Palmitoylation of amyloid precursor protein regulates amyloidogenic processing in lipid rafts. $J$ Neurosci 33, 11169-11183

100. Bhattacharyya, R., Fenn, R. H., Barren, C., Tanzi, R. E., and Kovacs, D. M. (2016) Palmitoylated APP forms dimers, cleaved by BACE1. PLoS One 11, e0166400

101. Sun, F., Chen, L., Wei, P., Chai, M., Ding, X., Xu, L., and Luo, S. Z. (2017) Dimerization and structural stability of amyloid precursor proteins affected by the membrane microenvironments. $J$ Chem Inf Model 57, 1375-1387

102. Dominguez, L., Foster, L., Meredith, S. C., Straub, J. E., and Thirumalai, D. (2014) Structural heterogeneity in transmembrane amyloid precursor protein homodimer is a consequence of environmental selection. $J$ Am Chem Soc 136, 9619-9626

103. Gotz, A., Mylonas, N., Hogel, P., Silber, M., Heinel, H., Menig, S., Vogel, A., Feyrer, H., Huster, D., Luy, B., Langosch, D., Scharnagl, C., Muhle-Goll, C., Kamp, F., and Steiner, H. (2019) Modulating Hinge Flexibility in the APP Transmembrane Domain Alters gamma-Secretase Cleavage. Biophys J 116, 2103-2120

104. Li, C. D., Junaid, M., Chen, H., Ali, A., and Wei, D. Q. (2019) Helix-Switch Enables C99 Dimer Transition between the Multiple Conformations. J Chem Inf Model 59, 339-350

105. Itkin, A., Salnikov, E. S., Aisenbrey, C., Raya, J., Glattard, E., Raussens, V., Ruysschaert, J. M., and Bechinger, B. (2017) Structural Characterization of the Amyloid Precursor Protein Transmembrane Domain and Its gamma-Cleavage Site. ACS Omega 2, 6525-6534

106. Lemmin, T., Dimitrov, M., Fraering, P. C., and Dal Peraro, M. (2014) Perturbations of the Straight Transmembrane alpha-Helical Structure of the Amyloid Precursor Protein Affect its Processing by gamma-Secretase. J Biol Chem 289, 6763-6774

107. Li, S., Zhang, W., and Han, W. (2017) Initial Substrate Binding of gamma-Secretase: The Role of Substrate Flexibility. ACS Chem Neurosci 8, 1279-1290

108. Song, Y., Mittendorf, K. F., Lu, Z., and Sanders, C. R. (2014) Impact of bilayer lipid composition on the structure and topology of the transmembrane amyloid precursor C99 protein. J Am Chem Soc 136, 4093-4096 
109. Hutchison, J. M., Shih, K. C., Scheidt, H. A., Fantin, S. M., Parson, K. F., Pantelopulos, G. A., Harrington, H. R., Mittendorf, K. F., Qian, S., Stein, R. A., Collier, S. E., Chambers, M. G., Katsaras, J., Voehler, M. W., Ruotolo, B. T., Huster, D., McFeeters, R. L., Straub, J. E., Nieh, M. P., and Sanders, C. R. (2020) Bicelles Rich in both Sphingolipids and Cholesterol and Their Use in Studies of Membrane Proteins. J Am Chem Soc 142, 12715-12729

110. Panahi, A., Bandara, A., Pantelopulos, G. A., Dominguez, L., and Straub, J. E. (2016) Specific Binding of Cholesterol to C99 Domain of Amyloid Precursor Protein Depends Critically on Charge State of Protein. J Phys Chem Lett, 3535-3541

111. Montesinos, J., Pera, M., Larrea, D., Guardia-Laguarta, C., Agrawal, R. R., Velasco, K. R., Yun, T. D., Stavrovskaya, I. G., Xu, Y., Koo, S. Y., Snead, A. M., Sproul, A. A., and Area-Gomez, E. (2020) The Alzheimer's disease-associated C99 fragment of APP regulates cellular cholesterol trafficking. $E M B O J$, e103791

112. Pierrot, N., Tyteca, D., D'Auria, L., Dewachter, I., Gailly, P., Hendrickx, A., Tasiaux, B., Haylani, L. E., Muls, N., N'Kuli, F., Laquerriere, A., Demoulin, J. B., Campion, D., Brion, J. P., Courtoy, P. J., Kienlen-Campard, P., and Octave, J. N. (2013) Amyloid precursor protein controls cholesterol turnover needed for neuronal activity. EMBO Mol Med 5, 608-625

113. Song, Y., Kenworthy, A. K., and Sanders, C. R. (2014) Cholesterol as a co-solvent and a ligand for membrane proteins. Protein Sci 23, 1-22

114. Wang, C., Ralko, A., Ren, Z., Rosenhouse-Dantsker, A., and Yang, X. (2019) Modes of Cholesterol Binding in Membrane Proteins: A Joint Analysis of 73 Crystal Structures. Adv Exp Med Biol 1135, 67-86

115. Nelson, L. D., Johnson, A. E., and London, E. (2008) How interaction of perfringolysin O with membranes is controlled by sterol structure, lipid structure, and physiological low $\mathrm{pH}$ : insights into the origin of perfringolysin O-lipid raft interaction. $J$ Biol Chem 283, 4632-4642

116. Veatch, S. L., and Keller, S. L. (2005) Seeing spots: complex phase behavior in simple membranes. Biochim Biophys Acta 1746, 172-185

117. Gorman, P. M., Kim, S., Guo, M., Melnyk, R. A., McLaurin, J., Fraser, P. E., Bowie, J. U., and Chakrabartty, A. (2008) Dimerization of the transmembrane domain of amyloid precursor proteins and familial Alzheimer's disease mutants. BMC Neurosci 9, 17

118. Munter, L. M., Voigt, P., Harmeier, A., Kaden, D., Gottschalk, K. E., Weise, C., Pipkorn, R., Schaefer, M., Langosch, D., and Multhaup, G. (2007) GxxxG motifs within the amyloid precursor protein transmembrane sequence are critical for the etiology of Abeta42. Embo J 26, $1702-1712$

119. Chen, W., Gamache, E., Rosenman, D. J., Xie, J., Lopez, M. M., Li, Y. M., and Wang, C. (2014) Familial Alzheimer's mutations within APPTM increase Abeta42 production by enhancing accessibility of epsilon-cleavage site. Nat Commun 5, 3037

120. Nadezhdin, K. D., Bocharova, O. V., Bocharov, E. V., and Arseniev, A. S. (2012) Dimeric structure of transmembrane domain of amyloid precursor protein in micellar environment. FEBS Lett 586, 1687-1692 
121. Kienlen-Campard, P., Tasiaux, B., Van Hees, J., Li, M., Huysseune, S., Sato, T., Fei, J. Z., Aimoto, S., Courtoy, P. J., Smith, S. O., Constantinescu, S. N., and Octave, J. N. (2008) Amyloidogenic processing but not amyloid precursor protein (APP) intracellular C-terminal domain production requires a precisely oriented APP dimer assembled by transmembrane GXXXG motifs. J Biol Chem 283, 7733-7744

122. Dominguez, L., Foster, L., Straub, J. E., and Thirumalai, D. (2016) Impact of membrane lipid composition on the structure and stability of the transmembrane domain of amyloid precursor protein. Proc Natl Acad Sci U S A 113, E5281-5287

123. Wang, H., Barreyro, L., Provasi, D., Djemil, I., Torres-Arancivia, C., Filizola, M., and Ubarretxena-Belandia, I. (2011) Molecular determinants and thermodynamics of the amyloid precursor protein transmembrane domain implicated in Alzheimer's disease. J Mol Biol 408, 879895

124. Cunningham, O., Andolfo, A., Santovito, M. L., Iuzzolino, L., Blasi, F., and Sidenius, N. (2003) Dimerization controls the lipid raft partitioning of uPAR/CD87 and regulates its biological functions. $E M B O J$ 22, 5994-6003

125. Huang, H., Simsek, M. F., Jin, W., and Pralle, A. (2015) Effect of receptor dimerization on membrane lipid raft structure continuously quantified on single cells by camera based fluorescence correlation spectroscopy. PLoS One 10, e0121777

126. Seno, K., and Hayashi, F. (2017) Palmitoylation is a prerequisite for dimerization-dependent raftophilicity of rhodopsin. J Biol Chem 292, 15321-15328

127. Winkler, E., Julius, A., Steiner, H., and Langosch, D. (2015) Homodimerization protects the amyloid precursor protein C99 fragment from cleavage by gamma-secretase. Biochemistry $\mathbf{5 4}$, 6149-6152

128. Bustamante, H. A., Rivera-Dictter, A., Cavieres, V. A., Munoz, V. C., Gonzalez, A., Lin, Y., Mardones, G. A., and Burgos, P. V. (2013) Turnover of C99 is controlled by a crosstalk between ERAD and ubiquitin-independent lysosomal degradation in human neuroglioma cells. PLoS One 8, e83096

129. Abramowski, D., Wiederhold, K. H., Furrer, U., Jaton, A. L., Neuenschwander, A., Runser, M. J., Danner, S., Reichwald, J., Ammaturo, D., Staab, D., Stoeckli, M., Rueeger, H., Neumann, U., and Staufenbiel, M. (2008) Dynamics of Abeta turnover and deposition in different beta-amyloid precursor protein transgenic mouse models following gamma-secretase inhibition. $J$ Pharmacol Exp Ther 327, 411-424

130. Gersbacher, M. T., Goodger, Z. V., Trutzel, A., Bundschuh, D., Nitsch, R. M., and Konietzko, U. (2013) Turnover of amyloid precursor protein family members determines their nuclear signaling capability. PLoS One 8, e69363

131. Kaether, C., Schmitt, S., Willem, M., and Haass, C. (2006) Amyloid precursor protein and Notch intracellular domains are generated after transport of their precursors to the cell surface. Traffic 7 , 408-415 
132. Kuhn, P. H., Wang, H., Dislich, B., Colombo, A., Zeitschel, U., Ellwart, J. W., Kremmer, E., Rossner, S., and Lichtenthaler, S. F. (2010) ADAM10 is the physiologically relevant, constitutive alpha-secretase of the amyloid precursor protein in primary neurons. EMBO J 29, 3020-3032

133. Barnes, N. Y., Li, L., Yoshikawa, K., Schwartz, L. M., Oppenheim, R. W., and Milligan, C. E. (1998) Increased production of amyloid precursor protein provides a substrate for caspase-3 in dying motoneurons. J Neurosci 18, 5869-5880

134. Weidemann, A., Paliga, K., Durrwang, U., Reinhard, F. B., Schuckert, O., Evin, G., and Masters, C. L. (1999) Proteolytic processing of the Alzheimer's disease amyloid precursor protein within its cytoplasmic domain by caspase-like proteases. J Biol Chem 274, 5823-5829

135. Skinkle, A. D., Levental, K. R., and Levental, I. (2020) Cell-Derived Plasma Membrane Vesicles Are Permeable to Hydrophilic Macromolecules. Biophys J 118, 1292-1300

136. Wang, X., and Pei, G. (2018) Visualization of Alzheimer's Disease Related alpha-/beta-/gammaSecretase Ternary Complex by Bimolecular Fluorescence Complementation Based Fluorescence Resonance Energy Transfer. Front Mol Neurosci 11, 431

137. Liu, L., Ding, L., Rovere, M., Wolfe, M. S., and Selkoe, D. J. (2019) A cellular complex of BACE1 and gamma-secretase sequentially generates Abeta from its full-length precursor. $J$ Cell Biol 218, 644-663

138. Mouilleron, H., Delcourt, V., and Roucou, X. (2016) Death of a dogma: eukaryotic mRNAs can code for more than one protein. Nucleic Acids Res 44, 14-23

139. Kochetov, A. V., Ahmad, S., Ivanisenko, V., Volkova, O. A., Kolchanov, N. A., and Sarai, A. (2008) uORFs, reinitiation and alternative translation start sites in human mRNAs. FEBS Lett 582, 1293-1297

140. von Stetten, D., Noirclerc-Savoye, M., Goedhart, J., Gadella, T. W., Jr., and Royant, A. (2012) Structure of a fluorescent protein from Aequorea victoria bearing the obligate-monomer mutation A206K. Acta Crystallogr Sect F Struct Biol Cryst Commun 68, 878-882

141. Kenworthy, A. K., Nichols, B. J., Remmert, C. L., Hendrix, G. M., Kumar, M., Zimmerberg, J., and Lippincott-Schwartz, J. (2004) Dynamics of putative raft-associated proteins at the cell surface. J. Cell Biol. 165, 735-746

142. Keller, P., Toomre, D., Diaz, E., White, J., and Simons, K. (2001) Multicolour imaging of postGolgi sorting and trafficking in live cells. Nat. Cell Biol. 3, 140-149

143. Vivas, M. G., Siqueira, J. P., Silva, D. L., de Bonia, L., and Mendonca, C. R. (2015) Investigation of the nonlinear absorption spectrum of all-trans retinoic acid by using the steady and transient two-photon absorption spectroscopy. RSC Adv 5, 74531-74538

144. Zor, T., and Selinger, Z. (1996) Linearization of the Bradford protein assay increases its sensitivity: theoretical and experimental studies. Anal Biochem 236, 302-308 